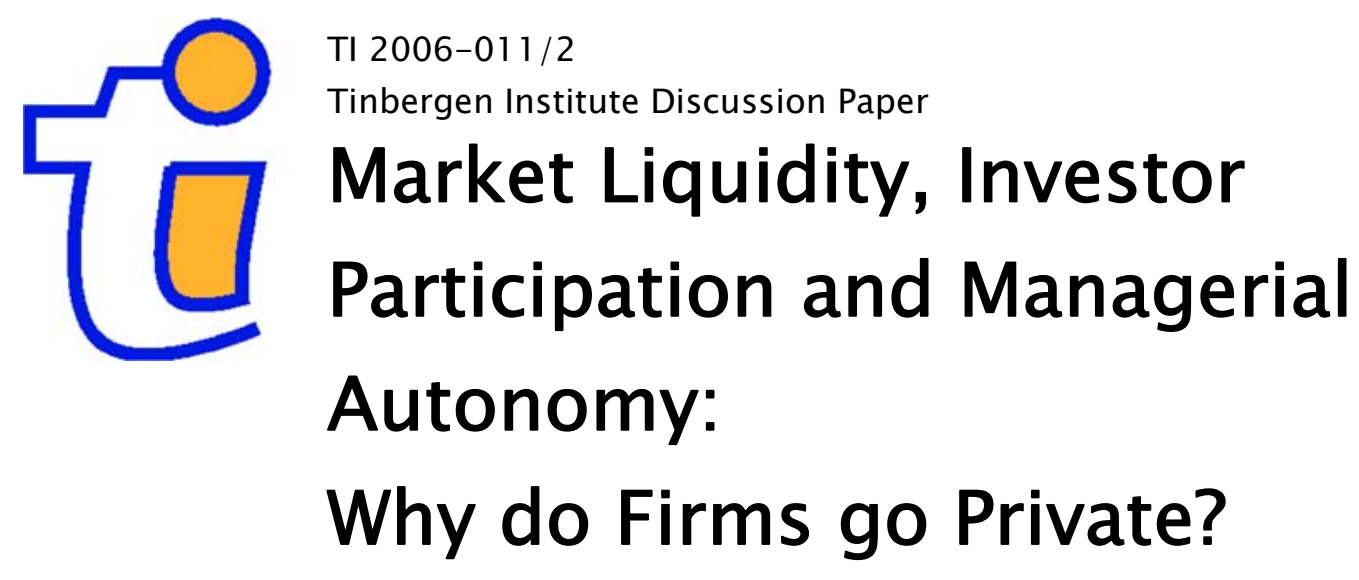

\author{
Arnoud W.A. Boot \\ Radhakrishnan Gopalan² \\ Anjan V. Thakor3
}

1 University of Amsterdam, Tinbergen Institute, and CEPR;

2 Stephen M. Ross School of Business, University of Michigan;

3 Olin School of Business, Washington University in St Louis. 


\section{Tinbergen Institute}

The Tinbergen Institute is the institute for economic research of the Erasmus Universiteit Rotterdam, Universiteit van Amsterdam, and Vrije Universiteit Amsterdam.

Tinbergen Institute Amsterdam

Roetersstraat 31

1018 WB Amsterdam

The Netherlands

Tel.: $\quad+31(0) 205513500$

Fax: $\quad+31(0) 205513555$

Tinbergen Institute Rotterdam

Burg. Oudlaan 50

3062 PA Rotterdam

The Netherlands

Tel.: $\quad+31(0) 104088900$

Fax: $\quad+31(0) 104089031$

Please send questions and/or remarks of nonscientific nature to driessen@tinbergen.nl.

Most TI discussion papers can be downloaded at http://www.tinbergen.nl. 


\title{
MARKET LIQUIDITY, INVESTOR PARTICIPATION AND MANAGERIAL AUTONOMY: WHY DO FIRMS GO PRIVATE?
}

\author{
by \\ Arnoud W. A. Boot, Radhakrishnan Gopalan and Anjan V. Thakor*
}

December 29, 2005

\footnotetext{
*Boot is from the University of Amsterdam and CEPR, a.w.a.boot@uva.nl, Gopalan is from the Stephen M. Ross School of Business at the University of Michigan, gopalanr@umich.edu and Thakor is the John E. Simon Professor of Finance, Olin School of Business, Washington University in St. Louis, thakor@wustl.edu. We thank Yhakov Amihud, Patrick Bolton, Kose John, Rafael Repullo, seminar participants at the 2005 ACLE/JFI Conference on "The Ownership of the Modern Corporation: Economic and Legal Perspectives on Private versus Publicly-listed Corporations", and seminar participants at Amsterdam, BI Oslo, Frankfurt, Georgetown, and NYU for useful comments.
} 


\begin{abstract}
We analyze a publicly-traded firm's decision to stay public or go private when managerial autonomy from shareholder intervention affects the supply of productive inputs by management. We show that both the advantage and the disadvantage of public ownership relative to private ownership lie in the liquidity of public ownership. While the liquidity of public ownership lets shareholders trade easily and supply capital at a lower cost, the liquidity-engendered trading also results in stochastic shocks to a firm's shareholder base. This exposes management to uncertainty regarding the identity of future shareholders and their extent of intervention in management decisions and in turn curtails managerial incentives. By contrast, because of its illiquidity, private ownership provides a stable shareholder base and improves these inputprovision incentives but results in a higher cost of capital. Thus, capital market liquidity, while being a principal advantage of public ownership, also has a surprising "dark side" that discourages public ownership. Our model takes seriously a key difference between private and public equity markets in that, unlike the private market, the firm's shareholder base, namely the extent of investor participation, is stochastic in the public market. This allows us to extract predictions about the effects of investor participation on the stock price level and volatility and on the public firm's incentives to go private, thereby providing a link between investor participation and firm participation in public markets. Lesser investor participation induces lower and more volatile stock prices, encouraging public firms to go private, whereas greater investor participation encourages younger firms to go public. Moreover, IPO underpricing is optimal because it is shown to lead to a higher and less volatile post-IPO stock price, greater autonomy for the manager and a higher supply of privately-costly managerial inputs.
\end{abstract}




\title{
MARKET LIQUIDITY, INVESTOR PARTICIPATION AND MANAGERIAL AUTONOMY: WHY DO FIRMS GO PRIVATE?
}

\author{
"The public be damned"
}

Wott Vanderbilt, Reply to Reporter, 1883

\section{INTRODUCTION}

When should a publicly-traded firm decide to go private? This question, which we address in this paper, is of central importance in the theory of the firm, and has been brought into sharper focus by recent events. During the 1990s, scores of companies went public, many quite young, with initial public offerings (IPOs) sold at unprecedented price-earnings multiples. However, since the precipitous decline of the stock market, the "going-public" wave appears to have been replaced by a delisting surge. The number of U.S. companies delisting was 35 in 1999, 66 in 2000 and 86 in 2003. Continuing this trend, 200 companies applied for delisting in $2004{ }^{1}$ Many have conjectured that the decline in stock prices after 2000 has induced firms to go private, a sort of flip side of the observation that IPOs are largely a bull-market phenomenon (e.g. Ritter and Welch (2002)). But why should privately-held firms go public when stock prices are high and publicly-traded firms go private when stock prices are low?

An additional development that has been suggested as a factor is the recent set of changes in the corporate governance of publicly-traded firms. In the U.S., this involved the passage of the Sarbanes-Oxley Act. This Act, passed in the wake of accounting scandals and other corporate abuses at highly-visible publicly-traded firms, is intended in part to restore investor confidence in the public stock market and ensure continued investor participation. But it has been suggested that this may increase the costs of being public and discourage public ownership. $^{2}$ There is, however, no formal theory that provides any link between a firm's decision to go private, investor participation in public capital markets, the level of its stock price, and the stringency of its corporate governance.

\footnotetext{
${ }^{1}$ A similar trend has been observed in Europe, where the number of firms going private went from 32 in 1998 to 50 in 2003, peaking during this period at 75 in 1999.

${ }^{2}$ For example, Deutsch (2005) reports in the New York Times: "The shares of Fidelity Bancorp have always been thinly traded, and its executives wondered why it bothered to be a public company at all. Still, they never really considered delisting the stock until Congress passed the Sarbanes-Oxley Act, with its myriad new reporting requirements, in 2002.

In November, the bank announced that it was "going dark" - delisting its stock from the Nasdaq market."
} 
Also unexplained is the stylized fact that the age of firms going public has been diminishing in the U.S., stock prices and corporate governance issues notwithstanding (see Fink et al., (2004)). Perhaps this has something to do with the development of the U.S. capital markets and enhanced investor participation. We do not really know. But it seems important for any theory of the choice of ownership structure to address this phenomenon as well.

We develop a theory that assigns center stage to investor participation and explores the potential interaction between investor participation and firm participation in the context of a publicly-traded firm's choice of whether to stay public or go private. We model a publiclytraded firm that has assets in place and also access to a restructuring opportunity. When the restructuring opportunity arrives, it is possible that the manager's posterior belief about its value will diverge from the shareholders' posterior belief. This can lead to disagreement about the optimal course of action. That is, disagreement can arise because beliefs are heterogeneous but rational in the sense of Kurz $(1994 \mathrm{a}, \mathrm{b}) .{ }^{3}$ We show that the optimal corporate governance regime will involve the manager being given some decision-making discretion or autonomy to overcome such disagreement and pursue the decision he thinks is best. In determining optimal managerial autonomy through the stringency of corporate governance, shareholders face the following tradeoff. On the one hand, shareholders want to make governance as stringent as possible to minimize the likelihood of the manager making a restructuring decision they don't like. On the other hand, greater stringency induces lower managerial effort in uncovering a good restructuring opportunity. We examine how this endogenously-determined managerial autonomy varies across public and private ownership.

A key aspect of our analysis is shareholder (investor) heterogeneity. Different investors may have different propensities to agree with the manager. This implies that the optimal degree of managerial autonomy as well as the valuation of the firm may differ depending on the investor base. With private ownership, the ownership base is stable because the relative illiquidity of this ownership discourages investors from frequent trading. This leads to stability in the alignment between the manager and the investors and hence in the autonomy given to the

\footnotetext{
${ }^{3}$ We assume that the restructuring opportunity represents a "novel" project that is not like the routine projects the firm has done in the past. Consequently, there is lack of hard historical data upon which to base an assessment of the opportunity that everybody can agree on. Thus, potential disagreement between the manager and the investors arises naturally because the information contained in payoff-germane historical data allows agents to rationally draw different prior beliefs, and is not due to incomplete information aggregation or asymmetric information. Heterogeneous priors have been used in various settings previously, e.g. Allen and Gale (1999), Garmaise (2001), Van den Steen (2004), and Morris (1995). Of course, the "genuine" disagreement we study can arise due to a variety of reasons other than the one we focus on, such as overconfidence on the part of either management or investors (Bernardo and Welch (2001), and Daniel, Hirshleifer and Subramanyam (1998)), excessive optimism (Manove and Padilla (1999)), or other psychological reasons like differences in intuition (Clarke and Mackaness (2001)). One could also think of the valuations of the manager and investors as potentially different private values in the context of auctions.
} 
manager. In the public capital market, the composition of shareholders is not fixed; it changes as investors trade in and out of the firm's shares because of market liquidity. Consequently, there is uncertainty about the level of alignment between the manager and investors.

For publicly-traded firms, uncertainty about the future ownership base due to trading means that managerial autonomy is set to be optimal given an expectation of what future investors will consider optimal. By contrast, in a private firm, corporate governance is determined by a private investor, who will not trade away his (illiquid) ownership, so managerial autonomy is chosen to be precisely optimal for the investor in question. In deciding whether to take a publicly-held firm private, the manager trades off the higher liquidity of public ownership against the more precisely-determined corporate governance stringency of private ownership. This tradeoff is affected by the cross-sectional heterogeneity among investors and the degree of investor participation in the public market. We also explore how firms can influence the level of this investor participation by underpricing their IPOs. Our model thus deals with the life-cycle of firms in terms of ownership structure. We start with publicly-traded firms that may decide at some point to go private, and then we go back and examine their IPO decision when they first went public. The common theme in this life cycle is the extent of investor participation in the firm's equity in the public market.

An important aspect of our analysis is that we endogenize the link between investor participation and the uncertainty the firm faces about the future ownership base and hence about the extent to which its governance structure will deviate from the optimum. Thus, the "butter and knife" in the tradeoff that determines ownership choice are essentially one and the same, namely the greater liquidity of public ownership relative to private ownership. On the one hand this greater liquidity lowers the firm's cost of capital and hence provides a relative benefit for public ownership, and on the other hand it creates greater uncertainty about the firm's ownership base and hence generates a relative disadvantage for public ownership.

Our main results are as follows. First, we show that the likelihood of a publicly-traded firm going private is decreasing in the level of its stock price, and increasing in the volatility of its stock price. Second, when a public firm goes private, it experiences an increase in value. Third, an increase in investor participation in the public equity market leads to an increase in the attractiveness of public ownership by positively affecting the firm's stock price level and variance and increasing the autonomy of its manager. Greater investor participation increases the expected valuation of the marginal investor holding the firm's stock, and thereby increases the expected stock price in the public market. Further, the variance of the marginal investor's valuation is shown to be smaller when there are more investors, which lowers the volatility of the firm's stock price. Greater investor participation also leads to higher expected agreement 
between the marginal investor and the manager, which increases optimal managerial autonomy with public ownership. Fourth, public firms will be taken private only at substantial premia above the pre-transaction stock prices. Fifth, an increase in investor participation in the public equity market encourages younger firms to go public. Sixth, we show that IPO underpricing is optimal because it increases investor participation in the public capital market, increases the post-IPO trading price and lowers its volatility, and leads to greater managerial autonomy.

This paper builds on Boot, Gopalan and Thakor (forthcoming), which also examines the entrepreneur's ownership choice, but does not focus on investor participation and heterogeneity, which is our key focus here. Both papers have in common a disagreement approach based on heterogenous priors, which is a departure from the usual approach employing homogenous priors and either asymmetric pre-contract information or exogenous private control benefits. As in Boot, Gopalan and Thakor (forthcoming), we will address why such a departure is needed, and indicate which of our results are unlikely to obtain in alternative common-priorbeliefs formulations. The rest of the paper is organized as follows. Section 2 contains the motivation for our approach and the literature review. Section 3 contains a description of the model. Section 4 has the analysis. Section 5 discusses model extensions and empirical predictions. Section 6 concludes. All proofs are in the Appendix.

\section{RELATED LITERATURE AND MOTIVATION FOR OUR APPROACH}

\subsection{The Related Literature}

Our work is related to a growing body of research on the determinants of public versus private ownership (e.g. Zingales (1995)). Some believe that public ownership comes with liquidity benefits but is too dispersed in ownership to offer the effective control that private ownership offers to investors (Bhide (1993) and Coffee (1991)). ${ }^{4}$ However, others have challenged this view. Bolton and von Thadden (1998) argue that some degree of ownership concentration in a public firm permits one to capture both the benefits of liquidity and control, whereas Bebchuck (1999) argues that an initial owner in a public company may defeat investors' attempts to control him by maintaining control through his ownership in order to protect his private control benefits. Maug (1998) presents a viewpoint similar to that of Bolton and von Thadden (1998)

\footnotetext{
${ }^{4}$ This improved investor control may permit investors to limit managerial expropriation of shareholder wealth or other forms of abuses such as those discussed by Jensen (1986). The point that private ownership offers better control has also been made by Black and Gilson (1998). The focus of this literature has been exclusively on private versus public equity. There are, however, papers that have also examined the firm's choice between private and public borrowing (e.g., Detragiache (1994)).
} 
but goes even further to suggest that investors in public firms could potentially exercise even better control over management than possible in a private firm. ${ }^{5}$

Burkart, Gromb and Panunzi (1997) introduce a note of caution with respect to the desirability of investor control over the manager. They suggest that a tradeoff exists between the ex post efficiency of shareholder control and its adverse ex ante effects on managerial incentives. In a slightly different vein, Pagano and Roell (1998) argue that the greater control in private ownership may actually become excessive in that in results in overmonitoring of the entrepreneur, inducing him to prefer public ownership.

While there are numerous differences between these papers and ours, the key distinguishing feature is that the existing literature has not addressed what constitutes the primary focus of our analysis, namely the manner in which a publicly-traded firm's choice of whether to go private is influenced by the crucial difference in the stability of the firm's investor base across private and public ownership and also by investor participation in the public equity market. ${ }^{6}$ This focus and our assumption of universal risk neutrality distinguish our paper naturally from the contributions of Admati, Pfleiderer and Zechner (1994), and Pagano (1993), who focus on the diversification and risk-sharing benefits of public markets. ${ }^{7}$

The paper closest to ours is the recent work of Boot, Gopalan and Thakor (forthcoming), which also examines the entrepreneur's choice between private and public ownership in a setting in which the manager has an endogenous control preference due to potential disagreement with investors. There are numerous important differences, however. In Boot, Gopalan and Thakor (forthcoming), the stability of the investor base and hence investor participation and the stringency of public market governance are held exogenously fixed. By contrast, the focus of this paper is on investor participation and its effect on the firm's future ownership base and stringency of public market governance, given the possibility of liquidity-induced trading with public ownership. That is, a novel aspect of this paper is its examination of the role of market liquidity with public ownership in simultaneously creating both the principal advantage and disadvantage of public ownership relative to private ownership. This allows us, in contrast to any of the earlier research, to show why public firms will tend to go private when their stock

\footnotetext{
${ }^{5}$ Although not addressing the issue of the choice between private and public ownership, Bennedsen and Wolfenzon (2000) show how the owner of the firm can choose an ownership structure with several- instead of one- large shareholders in order to form a coalition to acquire control. The coalition takes more efficient actions than any individual member would.

${ }^{6}$ The disclosure literature has also examined the link between investor participation and disclosure (see Bhattacharya and Nicodono (2001), for example). Maksimovic and Pichler (2001) argue that public ownership is accompanied by less flexible disclosure requirements than private ownership. Chemmanur and Fulghieri (1999) argue that the public capital markets involve duplicated monitoring costs.

${ }^{7}$ See, for example, Jensen (1986), Black and Gilson (1998), and Kaplan and Stromberg (2003).
} 
prices are low and exhibit high volatility, and also examine the link between IPO underpricing, investor participation, post-IPO price volatility and managerial autonomy.

\subsection{Motivation for Our Approach}

We now discuss our motivation for choosing a disagreement-cum-autonomy approach rather than the usual approaches based on agency or asymmetric information considerations. This motivation is related to four issues: real-world importance of joint control considerations, the relevance of endogenous security benefits and investor participation, the contrast of our framework with alternative models of entrepreneurial control, and the inadequacy of asymmetricinformation models in explaining the phenomena we focus on.

\section{Real-World Importance of Joint Control Considerations:}

There is evidence that control considerations are important in real-world reasons for staying private or going public, particularly when public-market corporate governance is considered excessively intrusive (Brau and Fawcett (2005)). While this may sometimes be due to agency reasons, there often appear to be cases in which entrepreneurs attach value to control not because they wish to enjoy personal consumption at the expense of the firm or are interested in maximizing something other than firm value. Rather, it is because they expect disagreement with investors despite congruent objectives. For example, it is difficult to imagine that entrepreneurs like Bill Gates, John Chambers, or Michael Dell were not motivated to maximize firm value when their companies went public by selling relatively small ownership fractions. Yet, issues of control have been important in all of these organizations. Our model of endogenous control preference accommodates such motivations.

One could argue that the standard private-control-benefits-agency model also generates a control-motivated rationale for ownership structure choice. However, there is a very important difference between models of exogenous private control benefits and our theory of endogenous control preference. In agency models where managers enjoy inefficient private control benefits or there are other agency problems, it is appropriate to view "security benefits" (cash flows) as being comonotonic with total benefits (cash flows plus private benefits) but private benefits as not being comonotonic with total benefits (see Aghion and Bolton (1992)). In these models, the first-best solution gives investors complete control, although frictions may preclude attaining the first best. ${ }^{8}$ By contrast, joint control is optimal in our model, with the manager and the investors being simultaneously in control and their relative bargaining strengths endogenously

\footnotetext{
${ }^{8}$ See for example, Jensen (1986), Black and Gilson (1998), and Kaplan and Stromberg (2003).
} 
determined. Joint control is often encountered in practice. In start-up firms, ultimate control over corporate decisions rests with the board (e.g. Lerner (1995) and Kaplan and Stromberg (2003)), and in most venture-capital-financed firms, board seats and control are shared by the venture capitalists and the entrepreneur (Kaplan and Stromberg (2003)). Similarly, in established firms there is de facto sharing of control between managers and investors with seats on the board or holdings that are significant enough to permit them to have influence. These practices conflict with existing theories that predict joint control is suboptimal. ${ }^{9}$

An inefficient-private-control-benefits model is Pagano and Roell (1998) where an entrepreneur who has full control can engage in socially-inefficient private benefits extraction. The entrepreneur would benefit from a credible precommitment not to extract private benefits, but investors need to monitor to limit entrepreneurial diversion, and monitoring incentives increase in the investor's ownership stake. Taking into account deadweight monitoring costs and the loss due to private benefit extraction, there exist optimal levels of monitoring and private benefits, with this optimum achieved through the entrepreneur's ownership structure choice. Private companies may experience excessive monitoring due to ownership concentration, thereby inducing the firm to go public. ${ }^{10}$ In discussing model extensions, Pagano and Roell (1998) note, as we do, that one additional disadvantage of public ownership is the entrepreneur's possible loss of control over the ownership base. In their model, this arises from the arrival of a new shareholder with a superior monitoring technology who buys out the previous monitoring shareholder and reduces the entrepreneur's personal diversion. With private ownership, the entrepreneur can veto such a transfer, but not with public ownership.

There are three key differences between Pagano and Roell's (1998) analysis and ours. First, the effect of investor participation in the public market on the firm's choice between private and public ownership is the focal point of our analysis, and absent in theirs. Second, the possible arrival of a shareholder with a superior monitoring technology unambiguously increases firm value (security benefits) with public ownership in Pagano and Roell (1998). ${ }^{11}$ By con-

\footnotetext{
${ }^{9}$ For example, in Aghion and Bolton's (1992) model of private control benefits, control optimally rests invariably with one party (typically the manager). Joint control is also inefficient in the property rights literature because of its adverse impact on the incentives of multiple parties to make firm-specific investments (e.g. Hart (1995)). Other papers where joint control is optimal are Boot Gopalan and Thakor (forthcoming) discussed earlier, Yerramilli (2004), and Gomes and Novaes (2001).

${ }^{10}$ Brennan and Franks (1997) provide supporting evidence. They show that in IPOs in the U.K. ownership use rationing in share allocations to limit the size of the largest shareholders, thereby reducing monitoring.

${ }^{11}$ That is, if we were to account for the impact of the possible loss of control over the shareholder base on ex ante firm value, we would find that this value would be higher and all shareholders would be better off due to the future loss of control because it would strengthen the entrepreneur's precommitment not to divert. In other words, this loss of control with public ownership is a disadvantage for the owner only ex post. He benefits ex ante. Pagano and Roell's (1998) main argument in favor of private ownership is the manager's larger ex post share of the surplus than with public ownership when an investor with superior monitoring arrives. Hence, a takeover occurs both with private and public ownership with the only difference beting the sharing of the
} 
trast, shareholder volatility with public ownership is an ex ante cost in our model and the entrepreneur is better off when this volatility is diminished via greater investor participation. Finally, we differ significantly in the empirical predictions. Pagano and Roell's (1998) main predictions is that public ownership is preferred when large amounts of external financing are needed and/or private benefit consumption is relatively efficient. Since we analyze the goingprivate transaction, it involves bidding for the shares of small investors and only the highest bidder is likely to succeed. Thus, a going-private transaction cannot be explained on the basis of managers taking firms private to preserve private benefit consumption or to avoid hostile takeovers. This also highlights that public-to-private transactions (our focus) are quite different from private-to-public transactions ( Pagano and Roell's (1998) focus), ${ }^{12}$ and is one reason why our predictions are different.

\section{Endogenous Security Benefits, the Role of Investor Participation and Contrast With the Standard Control Benefits Model:}

The seminal paper on private control benefits is Aghion and Bolton (1992), where both efficient and inefficient private control benefits are examined. There are several differences between Aghion and Bolton's (1992) framework and ours. First, private control benefits are typically exogenous, with the manager having a hard-wired preference for control. By contrast, the manager in our model has no innate preference for control His desire for autonomy emerges endogenously via the potential for disagreement. Second, with private benefits of control, there is a divergence of objectives between the manager and investor, which is absent in our model. Third, security benefits are exogenously fixed and identically valued by the manager and investors in models with private benefits of control. In our model, the very reason why autonomy matters is that security benefits may sometimes be valued differently by the entrepreneur and investors, and security benefits are endogenously determined.

As a consequence of these differences, the control implications in Aghion and Bolton (1992) are very different from ours. They consider three control regimes: exclusive entrepreneurial control, exclusive investor control, and state-contingent control wherein control transfers ex-

surplus.

${ }^{12}$ On the other hand, hostile going-private transactions can be explained on the basis of inefficient managerial benefits consumption. This explanation was offered for the hostile takeovers of the 1980s (Jensen (1986)). But this again cannot explain management-initiated going-private transactions or an increase in going-private transactions consequent to strengthening of public market regulation. Furthermore, these models of hostile takeovers equate the choice between public and private ownership with one between dispersed and concentrated ownership. Such a characterization maybe questionable because, the costs of accumulating a block in a liquid public market may not be very high (Bolton and von Thadden (1998)). Thus, while these models explain why concentrated holding makes sense in some situations, they do not explain why firms have to go private to achieve concentrated shareholding. By contrast, our analysis does not depend on ownership concentration, but rather on the stability of the ownership base with private ownership. 
clusively to one party ex post based on an observable signal. They find that when security benefits are comonotonic with total benefits, investor control is optimal and the first-best is achieved. When neither security benefits nor private benefits are comonotonic with total benefits, unilateral control allocations are dominated by state-contingent allocations. Joint control is never optimal. ${ }^{13}$ Since joint control plays a key role in the entrepreneur's ownership choice in our model, an Aghion-Bolton framework would not deliver the results we obtain.

To summarize, there are two essential differences between the private-control-benefits model and ours. First, unlike the private-control-benefits model, renegotiation-proof joint control is optimal in our framework. Second, the entrepreneur seeks to maximize security benefits, which are endogenously determined through the degree of agreement between the entrepreneur and investors, with the level of investor participation positively influencing security benefits. Any model of exogenous private control benefits in which security benefits are exogenous cannot have investor participation playing the central role it plays in our analysis.

\section{An alternative View of Entrepreneurial Control and Comparison With Our} Model:

There are agency models in which leaving the agent with some control is optimal, so one may wonder if these can be used instead of our framework. In these models, the principal can discipline the agent in an interim period to resolve agency problems, but doing so reduces the agent's hidden firm-specific investment (e.g. Aghion and Tirole (1997), Burkart, Gromb and Panunzi (1997) and von Thadden (1995)). As in our model, this may cause the principal to leave the agent with control in some future states. But unlike our paper, the ex post allocation of control in these papers is not joint; it always rests with one party or the other.

\section{The Possible Role of Asymmetric Information:}

Can asymmetric information (e.g. Stein (1989)) help us address the issues we focus on? We do not think so, for three reasons. First, to the extent that control issues appear in asymmetricinformation models, usually the better-informed party is given control (as in Burkart, Gromb and Panunzi (1997)), as opposed to having joint control. Second, if the entrepreneur knows more than investors, the Revelation Principle suggests that the truth would be elicited through a direct revelation mechanism, thereby achieving agreement over value-maximizing decisions, and eliminating control allocation issues. ${ }^{14}$ Third, asymmetric information models provide

\footnotetext{
${ }^{13}$ See Proposition 5 in Aghion and Bolton (1992). We quote from Aghion and Bolton (1992): "In our models, joint ownership is always (weakly) dominated by either unilateral or contingent control". (p.486).

${ }^{14} \mathrm{An}$ example of an asymmetric-information model of the choice between private and public ownership is Shah and Thakor(1988). In that paper an optimal mechanism is designed using the Revelation Principle and control issues are irrelevant.
} 
little help in understanding why a public firm would go private when its stock price is low and /or the volatility of this price is high. To explain a firm's decision to go private based on asymmetric information would require hypothesizing that asymmetric information problems with public ownership are more severe at low stock prices. However, existing models may well suggest the opposite. High future growth opportunities should lead to high market-tobook ratios and a greater fraction of the firm value coming from future opportunities rather than assets currently in place, thereby implying greater information asymmetries. Moreover, managers appear to issue equity when stock prices are high because of perceived wealth transfer gains, suggesting that informational asymmetries are greater at higher stock prices. ${ }^{15}$

\section{MODEL DESCRIPTION}

Our analysis starts out with an all-equity public firm may go private or stay public in anticipation of the arrival of a restructuring opportunity.

\subsection{Restructuring Opportunity and Disagreement}

We have an economy with universal risk neutrality and a riskfree interest rate of zero. Consider a publicly-listed firm in which the manager owns $\alpha \in(0,1)$ of the firm, and whose goal is to maximize the value of his shareholding in the firm. The remaining $1-\alpha$ is owned by public investors. The manager's ownership in the firm is his only wealth. There are five dates $0,1,2,3$ and 4 . At $t=0$, the firm has assets in place that will yield a non-stochastic cash flow of $S>0$ at $t=4$. At $t=0$, the manager makes two decisions: (i) whether to keep the firm public or to take it private; and (ii) given the chosen ownership mode, what governance structure to choose for the firm; the governance structure in turn determines the degree of autonomy for the manager in the event of disagreement with investors. Since we consider an existing public firm, it is possible that its governance structure has already been determined. Rather than take this as exogenous we examine the endogenization of the the governance mode at $t=0$. We discuss this in greater detail in Section 3.5. At $t=1$, the manager can choose to expend privately costly search effort e to find a restructuring opportunity ("project" from now) that will become available with probability $e$ at $t=3$. At $t=2$ the manager and investors learn about project availability. Trading by investors may occur at $t=2$; this will be described later. The manager's private cost of expending search effort $e$ is $\frac{\beta e^{2}}{2}$, where $\beta>0$ is a constant. The project will impact the cash flows being realized from existing assets at $t=4$.

\footnotetext{
${ }^{15}$ See, for example, Baker and Wurgler (2002).
} 
Conditional on learning about project availability at $t=2$, the manager and investors draw prior beliefs about its quality at $t=3$. Project quality can be one of two types: Good $(G)$ or Bad $(B)$. The cash flow from a $G$ project depends on a second managerial effort, which is the preparation effort- doing feasibility studies etc. If the manager expends preparation effort at $t=3$, he incurs a personal cost $\Psi>0$. The manager can choose not to expend this effort at no personal cost. With preparation effort, a $G$ project increases cash flow from $S$ to $X_{G}$. Without preparation effort, the $G$ project does not affect the cash flows. Irrespective of preparation effort, a $B$ project reduces the cash flow from $S$ to 0 .

There are thus two effort choices by the manager. The first is the search effort $e$, chosen at $t=1$, that affects the probability that a project will be available at $t=3$. Conditional on the project being available at $t=3$, there is a preparation effort that affects project profitability. These two efforts serve different purposes in the model. The subsequent analysis shows that the presence of search effort ensures that investors find it optimal to give the manager some autonomy, and the presence of preparation effort ensures that investors do not attempt to "force" the manager to undertake a project he believes is bad.

We let $\theta_{m}$ represent the manager's prior belief about the probability that the project is of type- $G$, and assume that $\theta_{m} \in\left\{\theta_{l}, \theta_{h}\right\}$, with $\theta_{h}>\theta_{l}$. Let $\delta \in(0,1)$ be the probability of the manager drawing $\theta_{h}$ and $1-\delta$ the probability of the manager drawing $\theta_{l}$. The value of the restructuring project as perceived by the manager depends on the manager's prior belief $\theta_{m}$ and his preparation effort choice. Define $X_{h} \equiv \theta_{h} X_{G}+\left[1-\theta_{h}\right] 0=\theta_{h} X_{G}$ and $X_{l} \equiv \theta_{l} X_{G}+\left[1-\theta_{l}\right] 0=\theta_{l} X_{G}$ as the perceived values of the project when the manager expends preparation effort and his priors are $\theta_{h}$ and $\theta_{l}$ respectively. We assume that $X_{l}<S<X_{h}$, so that the project is valuable (with preparation effort) when the prior belief about project quality is $\theta_{h}$ and it destroys value (regardless of effort) when the prior belief is $\theta_{l}$. Consequently, the manager will choose not to expend preparation effort whenever his prior about project quality is $\theta_{l}$, giving rise to a project value of $\theta_{l} S+\left[1-\theta_{l}\right] 0=\theta_{l} S<S$, which means that the manager will prefer not to undertake the project in this case.

The manager and investors may have different priors about the nature of the firm's project. Let $\theta_{i}$ represent the investors' prior probability that the project is of type- $G$, where, $\theta_{i} \in$ $\left\{\theta_{l}, \theta_{h}\right\}$. When $\theta_{m} \neq \theta_{i}$, the manager and the investors disagree about the desirability of the project. We permit $\theta_{m}$ and $\theta_{i}$ to be correlated as follows: $\operatorname{Pr}\left(\theta_{i}=\theta_{m}\right)=\rho \in[0,1]$, and $\operatorname{Pr}\left(\theta_{i} \neq \theta_{m}\right)=1-\rho$. Thus, $\rho$ represents the probability the manager and investors have a common prior belief about project quality. ${ }^{16}$ Each prior is privately observed and can neither be verified nor contracted upon.

\footnotetext{
${ }^{16}$ The model is thus general enough to include homogenous prior beliefs as a special case with $\rho=1$.
} 
If both the manager and the investors draw a prior belief of $\theta_{l}$, the manager does not expend preparation effort, and they agree not to undertake the project since they both perceive a negative net present value of $\theta_{l} S-S$. Similarly, if both the manager and the investors draw a prior of $\theta_{h}$, the manager expends preparation effort and there is mutual agreement to undertake the project which is perceived to have a positive net present value of $X_{h}-S$. Disagreement may arise when prior beliefs differ. If the manager draws $\theta_{l}$, then he will not expend preparation effort and will perceive the value of the project as $\theta_{l} S$. If in this case, investors draw a prior of $\theta_{h}$, then anticipating that the manager will not expend preparation effort, investors will perceive the value of the project as $\theta_{h} S$, and will also want to avoid the project.

However, when the manager's prior is $\theta_{h}$, he will expend preparation effort and will wish to implement the project, provided that the cost $\Psi$ is not prohibitive. ${ }^{17}$ If in this state the investors' prior belief is $\theta_{l}$, they will wish to reject the project. It is this disagreement that we focus on. Since the disagreement between the manager and investors comes about due to their different prior beliefs about project quality, there is no incentive for either to change these beliefs based on what the other believes. Beliefs will be revised only in the face of new information. Learning about the prior belief of someone who possesses no more payoff-relevant information provides no reason for the agent to update his own priors. ${ }^{18}$

Even though agents have heterogeneous priors, we assume that these prior beliefs are rational in the sense of Kurz (1994a,b). The essential aspect of the theory of rational beliefs for our analysis is that the observables in the economy that agents form beliefs about have the technical property of "stability" but not stationarity. ${ }^{19}$ That is, for beliefs to be rational, agents cannot have beliefs that are precluded by historical data. However, since a stable but non-stationary process is not generally uniquely identified even with countably infinite data points, there can be multiple rational beliefs that are consistent with the historical data. Not all these beliefs will conform to rational expectations; with non-stationarity, rational expectations would require agents to have information that cannot be derived from historical data.

The greater is the value of $\rho$, the greater is the likelihood of agreement between the manager and the investors; $\rho=1$ indicates perfect agreement while $\rho=0$ indicates perfect disagreement. The agreement parameter $\rho$ can be thought of as being affected by the attributes of the project

\footnotetext{
${ }^{17}$ A sufficient condition for the manager to invest $\Psi$ is given in Section 4 in expression (1). For now we assume that this condition is satisfied.

${ }^{18}$ See Kreps (1990) who views prior beliefs as part of the primitives of any model, and asserts that heterogenous priors represent a more general specification than homogenous priors.

${ }^{19}$ Kurz (1994a) shows that every stable process is associated with a specific stationary measure, and that multiple stable processes can give rise to the same associated stationary measure. While historical data can be used to construct the stationary measure, they cannot generally be used to distinguish between multiple stable processes associated with the same stationary measure.
} 
(i.e. the nature of the firm's business), the length of the time series of relevant historical data (e.g. the age of the firm), the manager's previous track record in managing similar projects of that type, and possibly also the general level of investor confidence in the corporate sector. If the project is one that the manager has previously dealt with successfully for a long time and investors are familiar with it as well, $\rho$ will tend to be high. Since project familiarity and confidence in the manager's prior track record can be expected to vary in the cross-section of investors, there can be heterogeneity among investors in the extent of their agreement with the manager, even when all investors and the manager have rational beliefs.

\subsection{Investor Participation in the Market}

We model heterogeneity of $\rho$ across investors by assuming that the public market is comprised of $N$ investors and that the $\rho$ for each investor at any point in time is an independent draw from a continuous probability distribution $G(\rho)$, with the associated density function $g(\rho)$ and support $\left[\rho_{l}, \rho_{h}\right]$. Whenever a project decision is to be made, the investors holding the firm's shares in the public market are likely to be the ones who have the maximum level of agreement with the manager as they assign the highest value to the firm. We assume that the investors with the highest $\rho$ have collectively sufficient wealth to own all the shares of the firm i.e., all the investors holding a firm's shares have the same $\rho$. Thus, although there is heterogeneity among public-market investors, for a particular firm there is homogeneity in the identity of its investors, in terms of their level of agreement with the manager.

\subsection{Liquidity Cost}

An important feature of our analysis is that investors experience interim liquidity needs. In particular, with probability 1 , investors require cash at $t=2$ in order to satisfy a liquidity need at that time. Investors can get cash either by selling an illiquid asset, which involves a liquidity penalty $L>0$, or by selling the shares of the firm. We assume, that investors face an interim liquidity with probability 1 to starkly highlight the cost of market liquidity. Our model can be easily extended to include a stochastic liquidity shock. ${ }^{20}$ In our model, the firm's shares are "private-value goods", i.e. investors can have different private valuations of the shares depending on their levels of agreement with the manager. Hence, any investor who wants to sell the shares would wish to sell to the investor with the highest valuation

\footnotetext{
${ }^{20}$ Including a stochastic liquidity shock will introduce an additional motive for trade. Investors may wish to sell shares even in the absence of a liquidity need, if there is an investor with a higher valuation. This is a potential benefit of market liquidity. Even in this case, if the probability of liquidity motivated trade is sufficiently large, all our model conclusions will be preserved.
} 
("maximal investor"). Finding such a buyer is facilitated by public listing since transactions occur in a well-defined market that accommodates active, low-cost trading, and the market price at any point in time reflects the valuation of the maximal investor. Any investor wishing to sell his shares can therefore do so without delay and without incurring any significant cost. $^{21}$ The high liquidity of public ownership thus manifests itself in our model in the form of enabling the investor to satisfy his liquidity need by selling the shares at a low cost. An important consequence of such trading is that it creates uncertainty about the identity of future shareholders and hence about $\rho$. Since the project selection decision is taken at $t=3$, it is only the $\rho$ at that point in time that matters. The $\rho$ at $t=3$ is equal to the $\rho$ of the "maximal investor" who buys shares at $t=2$, because we assume that investors who buy the firm's shares at $t=2$ retain their shares till $t=3$ and that there are no intertemporal shocks to $\rho$ for a given investor. At $t=0$, the manager, is uncertain about this $\rho$ because a new batch of $\mathrm{N}$ investors enter the market at $t=2$ when the old investors exit due to liquidity shock.

By contrast, private ownership lacks an analogous market transaction mechanism. Hence, when a private investor wishes to sell his shares, finding the "maximal investor" involves search, which could be both costly and time consuming. We assume that, for a privately-held firm, the time and cost involved in searching are high enough that a liquidity-motivated investor prefers to satisfy his liquidity need by selling some other illiquid asset in his endowment and incurring the penalty $L$, rather than incurring the higher cost associated with selling his ownership in the firm. ${ }^{22}$ Consequently, the relative illiquidity of private ownership results in the identity of the initially-identified investor remaining unchanged. The private investor's liquidity cost is $L$.

Note that the above costs of satisfying the investor's interim liquidity need with private ownership applies only when the restructuring project, with potential disagreement over its value, is involved. If the project does not arrive (which happens with probability $1-e$ ), then the firm's value is unambiguously $S$, and this is something everybody agrees on. Hence, absent the arrival of the project at $t=2$, the investor can costlessly sell his shares to any investor without incurring any search costs related to searching for a "maximal" buyer.

\subsection{Ownership Structure Possibilities}

The firm chooses at $t=0$ to either continue to be publicly-owned or become private. When the firm continues to be publicly-owned, the manager will perceive uncertainty at $t=0$ about the

\footnotetext{
${ }^{21} \mathrm{~A}$ potential cost of satisfying liquidity need even in the public market, is the cost of selling to an investor with a low valuation. We discusses this cost in Section 4.1.

${ }^{22}$ An alternative assumption is that the investor borrows from a bank using his ownership in the firm as collateral, and incurs a dissipative cost $L$ in doing so.
} 
agreement parameter $\rho$ that will prevail at $t=3$, since this parameter will be determined only after liquidity-induced trading occurs at $t=2$. If the firm decides to go private at $t=0$, then it must seek out a private investor. Once the investor has been found and the firm has been taken private, there will be no further trading that results in a change of ownership. Hence, there is no uncertainty about $\rho$ that will prevail at $t=3$.

\subsection{Managerial Autonomy Parameter}

Disagreement over project choice only matters when the manager wants to invest but investors don't. There must be a rule to resolve this disagreement. The structure of our model is that in this state both the manager and investors are simultaneously in control. Disagreement is resolved by determining the probability with which the manager gets to decide and the probability with which investors decide. This can be thought of as a bargaining game in which there is some probability with which the manager moves first and make a take-it-or-leave-it offer to investors and the probability with which investors get to move first with such an offer. If the take-it-or-leave-it offer is rejected, the firm comes to a standstill and the manager as well as investors get a payoff of 0 . The probability with which the manager moves first is called the autonomy parameter $\eta \in[0,1]$. Because the first mover in this game has all the bargaining power, $\eta$ is essentially the probability that the manager will be able to invest in the project when investors disagree with him; $1-\eta$ is the probability that shareholders will stop the manager from investing in this state. One could interpret $\eta$ as the corporate governance parameter that specifies the degree of control given to the manager.

Ceteris paribus the manager prefers more autonomy to less. This is not because he has an innate preference for control, but because greater autonomy gives him greater ability to maximize his assessment of security benefits. ${ }^{23}$ The autonomy parameter $\eta$ is endogenously determined (following the ownership choice) at $t=0$, after which the manager simply takes $\eta$ as fixed for his subsequent decisions. With either ownership mode, the optimal managerial autonomy is set to maximize the share price. Note that this way of specifying the allocation of control between the manager and investors, coupled with a result we will establish later that the optimal $\eta \in(0,1)$, means that we have joint control, which is a common feature of equity.

In our analysis, while we endogenize the governance arrangement with either ownership mode, we take the managerial share ownership $\alpha$ as exogenously fixed. This assumption simplifies the analysis and it is without loss of generality. Any optimal contract, designed to

\footnotetext{
${ }^{23}$ This is a crucial distinguishing feature of our approach from that of private benefits models, wherein control is preferred to preserve private benefits.
} 
provide effort incentives for the manager, will involve a non-zero managerial ownership stake. Given a positive managerial ownership stake, autonomy becomes relevant to the manager because he perceives the value of his ownership to be increasing in managerial autonomy. ${ }^{24}$ Allowing $\alpha$ to be endogenously determined as part of an optimal contract will not qualitatively affect our analysis. An important assumption throughout is that the manager does not have sufficient liquid assets to buy out the investors. With potential disagreement between the manager and the shareholders and the manager being indispensable for project implementation, the manager would want to buy out the investors. Insufficient managerial wealth precludes this. Thus, in our analysis of ex-post renegotiation also, the manager can only use his cash-flow rights to purchase control rights.

\subsection{Summary of Sequence of Events}

The sequence of events is as follows. At $t=0$, the manager decides whether to take the firm private or keep it public. If the manager chooses private ownership, the investor who has the maximum valuation for the firm at $t=0$ attempts to take the firm private by buying all the outstanding public shares at $t=0$. After the ownership mode is determined, the autonomy parameter $\eta$ is also determined at $t=0$. The manager invests in privately-costly search effort $e$ at $t=1$. This search effort affects the probability of the availability of the restructuring project at $t=3$. At $t=2$ both the manager and investors learn about project availability. After this, at $t=2$, investors have a need for liquidity, and if the firm is publicly traded, investors can satisfy this need by selling their shares in the market. If the firm is private, the private investor does not sell his shares and incurs a liquidity $\operatorname{cost} L$ in satisfying his liquidity need. If the manager learns that a project is available, he draws his private prior belief about project quality at $t=3$. Subsequently, he proposes the project to investors, who then draw their own prior belief about project quality at $t=3$. After this, the decision about whether to go ahead with the project is made at $t=3$. If the project is accepted, the manager chooses his preparation effort at $t=3$. This effort choice affects the cash flow enhancement possible with the restructuring. Cash flows are realized at $t=4$. Figure 1 summarizes the sequence of events. $^{25}$

\footnotetext{
${ }^{24}$ See Boot, Gopalan and Thakor (forthcoming) for an optimal financing contract involving a positive managerial ownership and a non-zero level of managerial autonomy.

${ }^{25}$ There are two aspects of the private-versus-public ownership choice that we have excluded from our analysis: the additional costs of public listing, and the potential monitoring benefits from having a few large private investors monitor management as opposed to having many small public shareholders do so. Both these aspects will strengthen the case for private ownership. But we believe that inclusion of these features will merely shift the cutoff in favor of private ownership, rather than change the qualitative nature of our results.
} 


\section{ANALYSIS}

We begin by analyzing the manager's choices of preparation effort and search effort for a given ownership mode and then go back and analyze the choice of ownership mode by comparing the relevant payoffs. The manager chooses the ownership mode and preparation and search efforts so as to maximize his expected wealth at $t=4$. Public ownership is examined first.

\subsection{Public Ownership}

We begin by analyzing the manager's choice to expend preparation effort after the manager knows the project is available. The condition given below guarantees that the manager will choose to expend preparation effort when he has drawn a prior belief $\theta_{h}$ that the project is type- $G$ and the project has been accepted:

$$
\alpha\left[X_{h}-S\right] \geq \Psi
$$

We assume henceforth that this condition is satisfied. ${ }^{26}$ Let us now turn to the choice of search effort $e$. If the manager chooses to continue with public ownership at $t=0$, then secondarymarket trading following the liquidity need at $t=2$ introduces uncertainty about the level of agreement between the manager and the investors at $t=3$, when the project acceptance decision is made. Let $\bar{\rho}$ be the expected level of agreement of the investors with the manager at $t=3$. Note that these investors are the ones who purchase shares at $t=2$ from the original investors; $\bar{\rho}$ is the expected value of the agreement parameter of these new investors.

We now determine the manager's choice of search effort $e$ by analyzing his payoff at $t=0$. The manager's expected payoff at $t=0$ with public ownership, as assessed by him, is given by:

$$
\begin{aligned}
V_{p u b}^{M} & =E\left(\alpha\left\{e \delta \rho\left[X_{h}-S\right]+e \delta[1-\rho] \eta_{p u b}\left[X_{h}-S\right]+S\right\}-e \delta\left\{\rho+[1-\rho] \eta_{p u b}\right\} \Psi-\frac{\beta e^{2}}{2}\right) \\
& =\alpha W_{p u b}^{M}-e \delta\left[\bar{\rho}+\{1-\bar{\rho}\} \eta_{p u b}\right] \Psi-\frac{\beta e^{2}}{2}
\end{aligned}
$$

where $W_{p u b}^{M} \equiv e \delta \bar{\rho}\left[X_{h}-S\right]+e \delta[1-\bar{\rho}] \eta_{p u b}\left[X_{h}-S\right]+S$ is the manager's assessment of the value of the firm at $t=0$. Note that the first term in $W_{p u b}^{M}$ is the increase in the firm's cash

\footnotetext{
${ }^{26}$ Observe that $\alpha\left[X_{l}-S\right]<0<\Psi$, which implies that a manager never undertakes preparation effort for a project he believes is bad.
} 
flow when there is a restructuring project (occurs with a probability $e$ ) and the investors and the manager both have prior beliefs $\theta_{h}$ (occurs with a probability $\delta \bar{\rho}$ ) and hence agree on implementing the project. The second term in $W_{p u b}^{M}$ is the increase in cash flow when there is a project, the manager draws a prior $\theta_{h}$ but the investors' prior belief is $\theta_{l}$ (occurs with a probability $\delta[1-\bar{\rho}]$ ). In this case the manager is able to undertake the project only with probability $\eta$. The last term in $W_{p u b}^{M}$ is the cash flow $S$ from assets in place, since in all states other than those reflected in the first two terms in $W_{p u b}^{M}$, the project is not accepted and the cash flow remains $S$. The two terms not involving $W_{p u b}^{M}$ in (2) are the private effort costs of the manager. The term $e \delta\left\{\bar{\rho}+[1-\bar{\rho}] \eta_{p u b}\right\} \Psi$ represents the preparation effort cost $\Psi$ multiplied with the probability $e$ of having a project, the conditional probability $\delta$ of the manager drawing a prior belief $\theta_{h}$ and the probability that investors will accept the manager's project choice, $\bar{\rho}+[1-\bar{\rho}] \eta_{p u b}$. The last term in (2) is $\frac{\beta e^{2}}{2}$, which is the cost of the manager's search effort. Once we have substituted for the manager's optimal search effort choice as a function of $\eta_{p u b}$, we will use (2) to determine the optimal public market $\eta$ that is set at $t=0$.

At $t=1$, the manager chooses his search effort $e$ to maximize $V_{p u b}^{M}$. We assume that the manager's shareholding is sufficient to satisfy his individual rationality (IR) constraint. We now have the following.

Lemma 1 The manager's uniquely optimal choice of effort level equals:

$$
e_{p u b}^{*}=\frac{\delta}{\beta}\left[\left\{\bar{\rho}+[1-\bar{\rho}] \eta_{p u b}\right\}\left\{\alpha\left[X_{h}-S\right]-\Psi\right\}\right]
$$

$e_{p u b}^{*}$ is strictly increasing in the expected level of agreement at $t=3(\bar{\rho})$, the managerial ownership fraction $(\alpha)$, and the autonomy parameter $\left(\eta_{p u b}\right)$, and is strictly decreasing in the effort disutility parameter $(\beta)$.

The intuition for why $e_{p u b}^{*}$ is increasing in $\bar{\rho}$ is that the probability that the project will actually be implemented is increasing in $\bar{\rho}$; thus, the manager's return to effort is greater when $\bar{\rho}$ is higher. Similar reasoning holds for the impact of the autonomy parameter $\eta_{p u b}$. The effects of managerial ownership $\alpha$ and the effort disutility parameter $\beta$ on effort are transparent.

Substituting (3) in (2) gives the total value of the manager's expected payoff at the optimum $e_{p u b}^{*}$ as perceived by the manager:

$$
V_{p u b}^{M *}(\eta)=\frac{\beta e_{p u b}^{* 2}}{2}+\alpha S
$$

The total value of the investors' share as perceived by them at $t=0$ is given by:

$$
V_{p u b}^{I}=E\left([1-\alpha]\left\{e \delta \rho\left[X_{h}-S\right]+e \delta[1-\rho] \eta_{p u b}\left[X_{l}-S\right]+S\right\}\right)
$$




$$
=[1-\alpha] W_{p u b}^{I}
$$

where $W_{p u b}^{I} \equiv e \delta \bar{\rho}\left[X_{h}-S\right]+e \delta[1-\bar{\rho}] \eta_{p u b}\left[X_{l}-S\right]+S$ is the investors' assessment of the value of the firm (the stock price) at $t=0$. Comparing (4) and (5) we see that a key difference between $W_{p u b}^{M}$ and $W_{p u b}^{I}$ arises due to the disagreement state when the manager draws a prior of $\theta_{h}$ and the investors draw a prior of $\theta_{l}$ (occurs with a probability $\delta[1-\bar{\rho}]$ ). In that state the investors perceive the NPV of the project as $X_{l}-S<0$, while the manager perceives it

as $X_{h}-S>0$. We can see that $W_{p u b}^{I}$ is increasing in $\bar{\rho}$. Thus, a higher level of agreement connotes a higher stock price.

An advantage of public ownership for investors is that it is possible to avoid the liquidity penalty $L$ by selling the shares in the market. But even when the investors sell the shares in the market, they incur a cost as the valuation of the buyer could be less than their own valuation. Thus, for the public investor to prefer selling over incurring the liquidity cost $L$, we require the following parametric restriction:

\section{Assumption 1}

$$
L>\left[\rho_{h}-\bar{\rho}\right] \delta \frac{2\left[X_{h}-S\right][1-\bar{\rho}]+\bar{\rho}\left[X_{h}+X_{l}-2 S\right]}{2[1-\bar{\rho}]}
$$

The condition ensures that the liquidity penalty $L$ is more than the difference between the valuation of the public investor and the expected price at which he can sell the shares in the market. To ensure that this condition is satisfied for all investors, we stipulate it for an investor with $\rho=\rho_{h}$, the maximum level of agreement for any investor with the manager. By contrast, with private ownership, we assume that the costs and time involved in searching for an investor are high enough such that the private investor prefers incurring the liquidity penalty $L$ to attempting to sell the shares.

\subsection{Public Market Governance Regimes and Investor Participation : How $\bar{\rho}$ is Determined}

We now examine how $\bar{\rho}$, the expected level of agreement of the investors with the manager at $t=3$, is determined. When the project implementation decision is made at $t=3$, the firm's shares will be held by the investor who has the maximum level of agreement with the manager. This is because, for a given level of managerial autonomy in the public market, this investor will have the maximum valuation for the firm's shares. Thus, $\bar{\rho}$ is the expected level 
of agreement of the "maximal investor" with the manager. ${ }^{27}$ When $\rho$ varies cross-sectionally and the $\rho$ for any investor is a random draw from a probability distribution, the highest value of $\rho$ among the $N$ investors - the $\rho$ of the "maximal investor" - is the $N^{t h}$ order statistic of $\rho$, say $\rho_{N}$, where $\rho_{N}=\max _{1 \leq i \leq N} \rho_{i}$.

Note that $\bar{\rho}$ is the expected value of the $N^{t h}$ order statistic, i.e. $E\left(\rho_{N}\right) \equiv \bar{\rho}$. Since $\rho$ in the public market is distributed according to the distribution function $G(\rho)$ and a density function $g(\rho)$, with support, $\left[\rho_{l}, \rho_{h}\right] \subset(0,1)$, we know from the standard properties of the $N^{\text {th }}$ order statistic that $\bar{\rho}$, is given by (see Galton and Pearson (1902)):

$$
\bar{\rho}=\frac{N !}{(N-1) !} \int_{\rho_{l}}^{\rho_{h}} G\left(\rho_{N}\right)^{N-1} g\left(\rho_{N}\right) \rho_{N} d\left(\rho_{N}\right)
$$

We now have Lemma 2.

Lemma 2 The expected value of the $N^{\text {th }}$ order statistic is increasing in $N$, i.e., $\frac{\partial \bar{\rho}}{\partial N}>0$. The variance of $\rho_{N}, \sigma_{N}^{2}$, is decreasing in $N$ as long as $T(N) \equiv\left\{\frac{g\left[G^{-1}\left(\frac{1}{N+1}\right)\right]}{N}\right\}^{-1}$ is non-increasing in $N$.

The intuition is that the greater the number of investors in the market, the higher is the agreement parameter of the maximal investor likely to be since there are more investors to choose from. Thus, $\bar{\rho}$ is increasing in $N$. Similarly, the greater the number of investors in the market, the smaller will be the variation in the level of agreement of the maximal investor, $\rho_{N}$. The condition given in Lemma 2 restricts the shape of the density function of $\rho$. Intuitively, the condition states that the density $g$ should not increase too rapidly with $\rho$. The uniform distribution, for which $T(N)$ decreases with $N$, is an example of an admissible distribution. Violation of this condition implies that a disproportionately large fraction of the population has a very high level of agreement with the manager. In this case, disagreement would not matter. We assume henceforth that this condition is satisfied.

Lemma 2 highlights two important effects of higher investor participation. The first effect is an increase in the expected value $(\bar{\rho})$ of the agreement parameter $\left(\rho_{N}\right)$, and the second is a reduction in its variance. Because there is a one-to-one relationship in our model between the expected value of $\rho_{N}$ and the level of the stock price with public ownership and also between the volatility of $\rho_{N}$ and the volatility of the stock price, this result implies that the level of the stock price will increase and its volatility will diminish as investor participation increases. This implies a negative correlation between stock returns and volatility that has been empirically

\footnotetext{
${ }^{27}$ This $\bar{\rho}$ will generally be different from the $\rho$ of the original investor at $t=0$ since that investor will sell out at $t=2$ to satisfy his interim liquidity need.
} 
documented (e.g. Black(1976)). The usual explanation given for this phenomenon is that the firm's financial leverage decreases with rising stock prices, and this reduces stock volatility. Our model shows that an increase in investor participation readily explains this inverse relationship between stock returns and volatilities, without having to rely on financial leverage.

We will now determine the public market governance parameter $\eta_{p u b}$, which is chosen at $t=0$ to maximize $V_{p u b}^{I}($ see $(5))$. We first need to make some regularity assumptions.

\section{Assumption 2}

$$
\rho_{l}\left[X_{h}-S\right]+\left[1-\rho_{l}\right]\left[X_{l}-S\right]>0
$$

This assumption is sufficient for investors to attach a positive expected value to the project, since (8) represents the expected value of the project as assessed by investors with $\rho=\rho_{l}$, the lowest possible agreement between the manager and investors. With this assumption, $V_{p u b}^{I}$ is increasing in managerial search effort. When (8) holds, $\eta_{p u b}$ has two opposite effects. One is a direct effect - an increase in $\eta_{p u b}$ results in a higher probability that the manager will implement a project that public shareholders disagree with; this decreases the stock price. The other is an indirect effect - an increase in $\eta_{p u b}$ increases the stock price by increasing managerial search effort. To ensure that the optimal autonomy parameter lies in $(0,1)$, we need both the direct and indirect effects to be sufficiently important. The assumption below is sufficient to guarantee this.

\section{Assumption 3}

$$
\begin{array}{r}
X_{h}+X_{l}>2 S \\
\rho_{h}<\frac{2\left[S-X_{l}\right]}{X_{h}-X_{l}}
\end{array}
$$

Note that (9) is unnecessary for $\rho_{l}>0.5$, since in that case Assumption 2 implies (9). With (9), the project is sufficiently valuable relative to its opportunity cost, whereas (10) ensures that the cost of disagreement $S-X_{l}$ is sufficiently large relative to the benefit of higher managerial effort so that the investors do not wish to give full autonomy to the manager. We can now derive the optimal autonomy parameter with public ownership, $\eta_{p u b}^{*}$, as follows.

Lemma 3 The optimal managerial autonomy parameter with public ownership, $\eta_{p u b}^{*}$, is given by the following expression:

$$
\eta_{p u b}^{*}=\frac{\bar{\rho}\left[X_{h}+X_{l}-2 S\right]}{2[1-\bar{\rho}]\left[S-X_{l}\right]} \in(0,1)
$$

$\eta_{\text {pub }}^{*}$ is increasing in $\bar{\rho}$, and the restructuring opportunity cash flow $\left(X_{h}\right.$ or $\left.X_{l}\right)$. 
Lemma 3 characterizes the properties of the public market governance regime. Managerial autonomy is increasing in $\bar{\rho}$. Intuitively, the greater the propensity of investors to agree with the manager, the lower the "cost" that such autonomy has for investors, and hence the less expensive it is for the manager to "purchase" this autonomy. The autonomy parameter $\eta_{p u b}^{*}$ is also increasing in the attractiveness of the restructuring opportunity $\left(X_{h}\right.$ or $\left.X_{l}\right)$ - the greater is $X_{h}$ or $X_{l}$, the lower is the cost of managerial autonomy.

The fact that $\eta_{p u b}^{*} \in(0,1)$ means that joint control is optimal. It is important to distinguish joint control in our model from the state-contingent control in Aghion and Bolton (1992). With state-contingent control, control transfers exclusively ex post to one party based on the realization of a contractible signal. ${ }^{28}$ There is no commonly-observed signal of this sort that agents can contract upon in our model. Moreover, when disagreement occurs, neither party views it as being ex post efficient to transfer control to the other party, so state-contingent exclusive control is never optimal. From Lemmas 2 and 3, we have the following proposition.

Proposition 1 Higher levels of investor participation in the public capital market, $N$, lead to higher levels of the expected agreement parameter, $\bar{\rho}$, and higher values of the optimal publicmarket managerial autonomy parameter, $\eta_{p u b}^{*}$.

This proposition states that greater investor participation in the equity market results in corporate governance that grants more decision-making autonomy to management. The intuition is that greater investor participation leads, on average, to higher agreement between the manager and shareholders (Lemma 2), paving the way for greater autonomy for the manager (Lemma 3). If firms with more analysts following them (i.e. the larger and better-known firms) can be viewed as those with greater investor participation, then this result says that the larger and better-known firms will optimally have more lax corporate governance as represented by greater managerial autonomy.

With this interpretation, Proposition 1 provides a testable prediction. If one views greater protection for managers against being replaced via takeovers as an empirical proxy for greater autonomy, then some evidence in support of the proposition is provided by Gompers, Ishi and Metrick (2003). They document that the values of their governance index for firms indicate that managers in larger firms enjoy greater protection from takeovers.

\footnotetext{
${ }^{28}$ The key assumptions in Aghion and Bolton (1992) that make joint control inefficient are that ex post both agents agree on the first-best action, and that in the event that joint control is granted, either party can bring the firm to a standstill by vetoing the action the other party wishes to take.
} 
This result seems quite specific to our disagreement-based autonomy framework. If we had only asymmetric information between investors and the manager along with private control benefits, then it would follow that greater investor participation would reduce this informational asymmetry $^{29}$ and investors would be able to exercise greater control over the manager to limit his private benefit extraction. Thus, an asymmetric information setup with private control benefits is likely to produce a prediction opposite to the one we have. Our next result addresses the attractiveness of public ownership for the manager.

Proposition 2 The manager's assessment of his security benefits with public ownership, $V_{p u b}^{M}$, is increasing in the level of investor participation in the public equity market.

This proposition implies that greater investor participation in the public equity market makes public ownership more attractive. This is intuitive. Greater investor participation increases the probability of finding investors with higher levels of agreement with the manager and hence induces higher valuations. The flip side of this is that low levels of investor participation will reduce the valuations of public firms, and this may provide a possible explanation for why relatively small firms, that complain about having received inadequate attention from security analysts and investors, have recently begun to go private. ${ }^{30}$

Again we know of no private-control-benefits model that would yield this result. For example, in Aghion and Bolton (1992), security benefits are exogenous and thus unaffected by investor participation. In our model, security benefits are endogenized via a managerialautonomy-contingent "investor approval" process that affects the expected value of security benefits for the manager.

\subsection{Private Ownership}

If the manager chooses private ownership at $t=0$, the investor with the highest valuation of the shares at $t=0$ will try to take the firm private. The level of managerial autonomy will now be set to maximize firm valuation from the point of view of this private investor. Moreover, unlike the case with public ownership, the private investor will not sell the shares when in need of liquidity, but will incur a liquidity cost.

\footnotetext{
${ }^{29}$ Large firms, which typically have more analyst following and greater investor participation, also exhibit lower adverse-selection components in their bid-ask spreads (see Stoll (1997)). The finding that large firms face lower informational asymmetries can be found in a number of papers (e.g. Hong, Stein and Lim (2000)).

${ }^{30}$ See Thorton (2004), for example.
} 
We shall now analyze the case of private ownership through backward induction. That is, we begin by evaluating the manager's search effort choice made at $t=1$, now as a function of the actual level of agreement between the manager and the private investor $\left(\rho_{p r}\right)$, and the managerial autonomy parameter $\eta_{p r}$ to be determined at $t=0$. Subsequently we shall determine the optimal level of managerial autonomy, $\eta_{p r}^{*}$, taking into account the manager's search effort choice calculated in the previous step. Our final step will be to analyze the manager's choice between private and public ownership. We do not present an analysis of the manager's preparation effort choice because that is exactly the same as with public ownership.

We first determine the optimal managerial search effort, $e_{p r}^{*}$, which is chosen to maximize the manager's expected payoff at $t=0$. This is similar to the public ownership case (see the objective function (2) and Lemma 1), but now evaluated at $\rho_{p r}$ rather than $\bar{\rho}$. Hence,

$$
e_{p r}^{*}=\frac{\delta}{\beta}\left[\left\{\rho_{p r}+\left[1-\rho_{p r}\right] \eta_{p r}\right\}\left\{\alpha\left[X_{h}-S\right]-\Psi\right\}\right]
$$

Managerial autonomy with private ownership, $\eta_{p r}^{*}$, is set so as to maximize the valuation of the private investor. The valuation of the private investor at $t=0$ is given by:

$$
\begin{aligned}
V_{p r}^{I} & =[1-\alpha]\left\{e_{p r}^{*}\left[\delta \rho_{p r}\left[X_{h}-S-L\right]+\delta\left[1-\rho_{p r}\right] \eta_{p r}\left[X_{l}-S-L\right]-\left[1-\delta\left\{\rho_{p r}+\left[1-\rho_{p r}\right] \eta_{p r}\right\} L\right]\right]+S\right\} \\
& =[1-\alpha] W_{p r}^{I}
\end{aligned}
$$

where $W_{p r}^{I} \equiv e_{p r}^{*}\left[\delta \rho_{p r}\left[X_{h}-S-L\right]+\delta\left[1-\rho_{p r}\right] \eta_{p r}\left[X_{l}-S-L\right]-\left[1-\delta\left\{\rho_{p r}+\left[1-\rho_{p r}\right] \eta_{p r}\right\} L\right]\right]+S$ is the investor's valuation of the firm at $t=0$. This expression is similar to that for $W_{p u b}^{I}$ except that the private investor's level of agreement $\rho_{p r}$ may differ from the expected level of agreement $\bar{\rho}$, and the private investor incurs a liquidity $\operatorname{cost} L$ whenever the project is implemented. The following lemma characterizes the optimal managerial autonomy with private ownership.

Lemma 4 The optimal managerial autonomy parameter, $\eta_{p r}^{*}$, is given by the following expression:

$$
\eta_{p r}^{*}=\frac{\delta \rho_{p r}\left[X_{h}+X_{l}-2 S\right]-L}{2 \delta\left[1-\rho_{p r}\right]\left[S-X_{l}\right]} \in(0,1)
$$

Observe that $\eta_{p r}^{*}$ is increasing in the agreement between the private investor and the manager $\left(\rho_{p r}\right)$ and the present value of the project $\left(X_{h}\right.$ or $\left.X_{l}\right)$, and decreasing in the liquidity cost $(L)$. The intuition for much of this lemma is similar to that for Lemma 3. The reason why $\eta_{p r}^{*}$ is decreasing in $L$ is as follows. From the investor's standpoint, the purpose of giving autonomy to the manager is to induce the desired search effort, $e$; see from (12) that $e_{p r}^{*}$ is increasing in $\eta_{p r}$. An increase in $L$ reduces the value of the project to the investor (see (13)) and hence the 
marginal value of inducing the manager to expend search effort. This leads to a lower optimal autonomy parameter. Since $L>0$ with private ownership and $L=0$ with public ownership, the implication is that the autonomy that is optimal at the same level of agreement, $\rho$, is lower with private ownership than with public ownership.

\subsection{Renegotiation at the time of Project Choice}

The corporate governance structure stipulates that in case of disagreement the manager gets to decide with probability $\eta$ and the investors get to decide with a probability $1-\eta$. Since $\eta$ is chosen to be ex ante efficient, it is natural to ask whether there are any ex post incentives to renegotiate the original control structure. This is potentially important in the disagreement state in which the manager wants to go ahead with the project and the investor wants to reject it. We can show that when the managerial ownership $\alpha$ is neither too high nor too low, the ex ante optimal governance structure is renegotiation proof. The following lemma formalizes the sufficient condition for renegotiation-proofness.

Lemma 5 The optimal private-ownership autonomy parameter is renegotiation proof iff

$$
\frac{S-X_{l}}{X_{h}-X_{l}}<\alpha<\frac{X_{h}\left[S-X_{l}\right]}{X_{h}-X_{l}}
$$

The intuition for this condition is as follows. When the managerial ownership is very high, foregoing the project is too costly for the manager and hence he optimally buys back full control from the investor. Similarly, when the investor's ownership is very high, going ahead with the project is too costly for the investor and hence he will find it optimal to buy back control from the manager. We will assume henceforth that the manager's ownership share $\alpha$ is neither too high nor too low in the sense that it satisfies (15).

\subsection{Choice Between Public and Private Ownership}

The following proposition characterizes the manager's choice between private and public ownership.

Proposition 3 There exists a cutoff value of the agreement parameter $\rho_{p r}$, call it $\hat{\rho}$, with $\hat{\rho}>\bar{\rho}$, such that the manager will choose private ownership if and only if $\rho_{p r}>\hat{\rho}$. The probability of the firm going private is thus decreasing in $\widehat{\rho}$. The cutoff $\hat{\rho}$ is increasing in: the 
expected level of agreement in the public market, $\bar{\rho}$, the liquidity cost of private ownership, $L$ and the level of investor participation in the public market, $N$.

Proposition 3 highlights the factors that influence public firms to go private. The manager prefers private ownership whenever he encounters a private investor with a sufficiently high level of agreement with him. This is because the optimally-chosen managerial autonomy as well as the private investor's valuation of the firm are both increasing in $\rho_{p r}$, the private investor's level of agreement with the manager. ${ }^{31}$ The reason why $\hat{\rho}$, the cutoff value of the agreement parameter above which private ownership is preferred, is strictly greater than $\bar{\rho}$ is because of $L$, the liquidity cost with private ownership. From Lemma 4 we know that as $L$ increases, the optimal managerial autonomy with private ownership, $\eta_{p r}^{*}$, decreases, so the attractiveness of private ownership is decreasing in $L$. This is why $\hat{\rho}$, the hurdle for private ownership to be preferred, increases with $L$. The cutoff $\hat{\rho}$ is increasing in the expected public market agreement parameter, $\bar{\rho}$, because public ownership becomes relatively more attractive with an increase in $\bar{\rho}$. Finally, $\widehat{\rho}$ is increasing in the level of investor participation, $N$, because greater investor participation leads to a higher $\bar{\rho}$, and thus enhanced attractiveness of public ownership.

The result that the probability of going private is decreasing in the liquidity cost $L$ may be encountered in other formulations and is not unique to our model. However, as we discussed earlier, the result that the probability of private ownership is decreasing in public-market investor participation is very specific to our model, since this result stems from the impact that investor participation has on the degree of alignment between the manager and investors. Thus, it is unlikely to be encountered in models with exogenous private benefits of control.

We now present a comparison of the manager's effort choices with private and public ownership. This result will be useful in examining the valuation of the private investor relative to the firm's stock price with public ownership.

\footnotetext{
${ }^{31}$ We have not modelled the costs the firm incurs in being publicly listed. This is not to say that these costs are trivial, because they can be quite significant, especially for small firms. For example, Deutsch (2005) reports in The New York Times: "Donald Neel, the chief executive officer of Fidelity, which is based in Evansville Indiana, says the bank's accounting and management would easily pass scrutiny. But he says going dark will save $\$ 300,000$ per year a substantial sum for a bank with just $\$ 200$ million in assets." However, introducing this cost will simply shift the cutoff $\hat{\rho}$ for private ownership in our model, without changing the qualitative insights. Thinking about the listing cost does explain though why the private investor would not want to keep the firm publicly listed after acquiring all the shares. The benefit of public ownership to the investor is the ability to relatively costlessly sell in the public market to another investor who assigns a valuation that is equal to or greater than his own. But for the private investor with $\rho_{p r}>\widehat{\rho}>\bar{\rho}$, the probability at $t=0$ of finding an investor at $t=2$ who assigns a higher valuation to the firm is very small. Thus, even a small listing cost will make it inefficient for the private investor to want to publicly list a firm that he owns $100 \%$ of. In any case, in our analysis the choice of ownership mode is made by the manager at $t=0$, not the non-managing investor.
} 
Lemma 6 Whenever the manager strictly prefers private ownership, his optimal effort choice with private ownership, $e_{p r}^{*}$, strictly exceeds that with public ownership, $e_{p u b}^{*}$.

The intuition is as follows. The manager's total payoff with any ownership mode is uniquely characterized by, and is increasing in, his search effort $e$. This can be seen from (4) and the analogous expression with private ownership. ${ }^{32}$ Hence, if the manager prefers private ownership, it is because his payoff with private ownership is greater than with public ownership, which then implies that his search effort is greater with private ownership than with public ownership. Because a higher search effort means a higher firm value, an implication of Lemma 6 is that a public firm that goes private is worth more after going private. Evidence consistent with this implication appears in Smith (1990) and Bull (1989).

Although the manager might prefer private ownership at $t=0$, he will not be successful in taking the firm private unless the private investor can purchase all the publicly-traded shares at $t=0$. This will happen only if the firm value with private ownership is greater than the value with public ownership. As the next proposition shows, whenever the manager prefers private ownership, the private investor's valuation is also greater than the public firm's stock price. This permits the firm to go private when the manager prefers private ownership.

Proposition 4 Whenever the manager strictly prefers private ownership, the valuation of the private investor is higher than the firm's stock price if it continues with public ownership.

The intuition is as follows. Lemma 6 tells us that the manager prefers the ownership mode that maximizes his search effort. From (5) and (13) we know that the stock price with public ownership and the private investor's valuation are both increasing in managerial search effort. Apart from the different agreement and autonomy parameters, a key difference between the stock price with public ownership and the private investor's valuation is the liquidity cost $L$ which, ceteris paribus, decreases the private investor's valuation (direct effect). The liquidity cost also reduces the managerial autonomy parameter with private ownership (see the discussion following Lemma 4), and this increases the private investor's valuation (indirect effect). With our assumption of a quadratic function for effort and constant liquidity costs, the direct and indirect effects cancel out. As a result, a comparison of the stock price with public ownership and the private investor's valuation reduces to a comparison of the managerial search efforts across the two ownership modes. Hence, whenever the manager strictly prefers private ownership, the investor's valuation with private ownership will also be strictly greater than

\footnotetext{
${ }^{32}$ The analogous expression is $V_{p r}^{M *}=\beta e_{p r}^{* 2}+\alpha S$.
} 
the public firm's stock price. This proposition also generates the prediction that going-private transactions will occur only at significant premia over the pre-announcement stock price.

Observe that since the private investor is buying out all the outstanding publicly-traded shares, there will not be free riding by individual shareholders as in Grossman and Hart(1980). But the price at which the private investor acquires these shares needs to be pinned down. The fact that the private investor's valuation is greater than the stock price with public ownership ensures that the going-private transaction generates a surplus. We assume that the public shareholders get a fraction $\gamma$ of the surplus while the private investor gets $1-\gamma$. Thus, the price at which the private investor can acquire the shares is $P=W_{p u b}^{I}+\gamma\left[W_{p r}^{I}-W_{p u b}^{I}\right]^{33}$

Our analysis also permits us to say something about the attractiveness of public ownership and the level and volatility of the firm's stock price. Private ownership will be preferred in situations in which the investors' expected agreement with managerial decisions, $\bar{\rho}$, is relatively low, leading to a relatively low public-market managerial autonomy parameter, $\eta_{p u b}^{*}$. This implies that we will have public firms going private more often when stock prices are low (characterized by low $\bar{\rho}$ ) than when stock prices are high. If we assume that low and high valuations are correlated with general market conditions (e.g. due to investor sentiment), then this result is consonant with the empirical evidence that IPOs are largely a bull-market phenomenon (see, for example, Ritter and Welch (2002) as well as the anecdotal evidence mentioned in the Introduction). Moreover, we know from Proposition 3 that the probability of the public firm going private increases as $N$, the level of investor participation in the public market, decreases. Moreover, we know from Lemma 2 that a decrease in $N$ increases the volatility of the public firm's stock price. Hence, the prediction is that higher stock price volatility encourages public firms to go private.

While it is conceivable that our result that public firms will go private when they are trading at relatively low prices could be obtained with alterative (perhaps simpler) models, the result that high price volatility will also induce such behavior seems special to our model since this result depends on the simultaneous effect of investor participation on price volatility and agreement between the manager and investors. None of the existing models that employ asymmetric information or private control benefits would generate this result.

\footnotetext{
${ }^{33}$ We can generate such a surplus-sharing rule via an explicit Nash bargaining game.
} 


\section{MODEL EXTENSIONS AND EMPIRICAL PREDICTIONS}

In this section we discuss whether mechanisms could be designed in the public capital market that facilitate greater investor stability, and also provide extensions of the model wherein we explain the firm's decision to first go public as a function of $N$, the number of investors in the public market, and then examine how $N$ may be endogenized. We close the section with a discussion of the main empirical predictions of the analysis.

\subsection{Lock-up Agreements and Investor Stability in the Public Market}

In our model, private ownership ensures that the private investor holds on to the firm's shares until $t=3$. This provides stability to the level of agreement between the manager and the investor, which facilitates better matching between $\eta_{p r}$ and $\rho_{p r}$ and ensures a higher level of managerial effort. Can this ever be achieved with public ownership? That is, can the investor with $\rho=\rho_{p r}$ buy all the public shares at $t=0$, fix the level of managerial autonomy to maximize his valuation and commit not to sell the shares until $t=3$ even with public ownership? The answer is no. This is because the investor suffers a liquidity need in the future and this makes any commitment by him not to sell his shares in the future time-inconsistent. Anticipating such a sale, the manager will not expend the optimal search effort. Consequently, public ownership will not result in the same search effort as private ownership. Thus, somewhat ironically it is the very liquidity of the public equity market that keeps a publicly-traded firm from being able to elicit the same high level of search effort from the manager as a privately-held firm. In our model, the role of private ownership is to prevent any sale of shares by the private investor, which ensures investor stability and relatively high managerial search effort. This role can not be duplicated by a liquid public market.

While public-market liquidity does create volatility in the firm's ownership base, there are several mechanisms that could, at least temporarily, dampen this volatility. For example, venture capitalists opt for a partial exit via an IPO, but often continue to retain a sizeable ownership stake in the firm even after the IPO. This guarantees a certain degree of stability in the ownership base, at least for some time. Similarly, lock-up agreements compel managers and investors to hold on to their shares following an IPO, which again improves the stability of the ownership base.

IPO transactions also sometimes include financial inducements for investors to hold on to their shares. For example, in the 1998 Deutsche Telecom IPO, retail (non-institutional) purchasers of shares in the IPO were offered an $8 \%$ reward (in terms of a lower IPO price) if 
they held on to their shares for at least 24 months.

The existence of dual-class shares is also sometimes rationalized on the grounds that such shares facilitate investor stability. The voting shares, which are typically held by management and related parties, are typically less liquid and are also accompanied by transfer restrictions and hence contribute to greater investor stability.

While these examples help to see how our theory illuminates the popularity of practices that increase public ownership stability, the fact remains that the liquidity of public ownership is an undeniable force in making public ownership less stable than private ownership. The practices we have discussed may make reduce the shareholder-instability disadvantage of public ownership, but are unlikely to completely eliminate the dark side of liquidity.

\subsection{Investor Participation and the Age at Which the Firm Goes Public}

Our analysis can be used to gain some insight into when in its life cycle a firm will go public. The longer a firm has survived as a private entity with a track record, the longer will be the time series of historical data about the firm. This confines the set of rational beliefs and lowers the likelihood of disagreement between the manager and investors. We model this by assuming that the distribution of $\rho$ is a function of the firm's age $a$, with $\frac{\partial G(\rho)}{\partial a}<0$. This implies for any two ages $a_{1}$ and $a_{2}$, with $a_{1}>a_{2}, G\left(\rho \mid a=a_{1}\right)$ first-order stochastically dominates $G\left(\rho \mid a=a_{2}\right)$.

We have thus far taken the extent of investor participation, $N$, as exogenous. It is clear that $N$ may change over time. This can happen for a variety of reasons, including lower transactions costs for trading, improved market liquidity, etc. This now leads to the following result.

Proposition 5 Holding all other parameters fixed, there exists a critical firm age $a^{*}$ such that the firm stays private until $a \leq a^{*}$ and goes public when $a>a^{*}$. Moreover, $a^{*}$ is decreasing in the extent of public-market investor participation, $N$, i.e. $\frac{\partial a^{*}}{\partial N}<0$.

The intuition underlying the result that the firm goes public only when it is sufficiently old is that $\bar{\rho}$ stochastically increases with the firm's age, and public ownership looks relatively more attractive at higher values of $\bar{\rho}$ (see Proposition 3). The reason why higher levels of investor participation in the public equity market encourage younger firms to go public is that an increase in $N$ makes public ownership more attractive for any firm because it increases $\bar{\rho}$. Since $\frac{\partial G(\rho)}{\partial a}<0$, the $\bar{\rho}$ for a given firm is increasing in $a$. Hence, as $N$ increases, it takes a 
smaller increase in $a$ to make public ownership more attractive than private ownership. Because this result is driven by investor participation, it is specific to our model.

This prediction has empirical support in the recent work of Fink, Fink, Grullon and Weston (2004), who show that the average age of firms going public declined from forty years in the 1960s to five years in the 1990s. This was also a period during which public-market investor participation increased significantly. Further evidence can be found in international comparisons. For example, a typical IPO in the US, where investor participation is higher than in Italy, involves firms that are much younger than the firms doing IPOs in Italy. ${ }^{34}$

\subsection{Endogenizing the level of investor participation $N$}

A key variable in our analysis is $N$, the level of investor participation in the public equity market. It affects the level of managerial autonomy for public firms as well as the choice between public and private ownership. We now discuss one possible way in which $N$ can be endogenously determined by a firm through actions taken during its Initial Public Offering (IPO), and discuss the tradeoffs involved in the firm's optimal choice of $N$.

We extend the model backwards to date $t=-1$ when the representative firm (analyzed earlier) is privately owned with the owner-manager owning $100 \%$ of the equity. At date $t=-1$ the firm goes public and the owner manager sells a fraction $1-\alpha$ of the shareholding of the firm in the IPO. We assume that $1-\alpha$ is exogenously given. The firm fixes the price of the IPO so as to maximize the total proceeds. The economy consists of a total of $\bar{N}$ potential investors who could invest in the firm's IPO. Investors have to incur a trading cost to subscribe to the firm's shares. This cost can be thought of as the sum of the costs of opening a brokerage account, doing research about the company, etc. We assume that this cost, $c$, differs across investors, and is distributed according to the distribution function $F(c)$ with an associated density function $f(c)$. Let $[0, \bar{c}]$ be the support of $f(c)$. The fraction of investors with trading cost less than or equal to $c$ is given by $F(c)$.

The revised time line is as follows. At date $t=-1$ a private firm sells a fraction $1-\alpha$ of its ownership to the public in an IPO. The firm fixes the price of the shares in the IPO so as to maximize the net proceeds. Simultaneously, investors decide whether to participate in the firm's IPO. For simplicity, we assume that the IPO shares are sold pro rata to all participating investors. ${ }^{35}$ After the IPO, each investor individually realizes his level of agreement with the

\footnotetext{
${ }^{34}$ Pagano, Panetta and Zingales (1998) report that a typical firm doing an IPO in Italy is 6 times older than a typical firm doing an IPO in the US.

${ }^{35}$ This assumption is not inconsistent with our earlier analysis in Section 4.2 , wherein we argued that at $t=3$
} 
manager, $\rho$. All this occurs between date $t=-1$ and date $t=0$. The subsequent events unfold as described earlier. That is, at date $t=0$ the manager decides the ownership mode (whether to take the new-public firm private again) and so on. The one key assumption we employ in our analysis is that individual investors' agreement parameters are unknown at the IPO stage.

We analyze the firm's pricing problem by backward induction. For a given level of investor participation $N$, we estimate the expected stock price at $t=0, E\left(P_{0}(N)\right)$. Subsequently, we solve the firm's problem and determine the price of the shares in the IPO. The expected stock price at $t=0$ can be expressed as

$$
\begin{aligned}
E\left(P_{0}(N)\right)= & Q_{N}(\widehat{\rho}(N)) W_{p u b}^{I}(N)+\left[1-Q_{N}(\widehat{\rho}(N))\right] \gamma E_{N}\left(W_{p r}^{I}(\rho) \mid \rho>\widehat{\rho}(N)\right) \\
& +\left[1-Q_{N}(\widehat{\rho}(N))\right][1-\gamma] W_{p u b}^{I}(N)
\end{aligned}
$$

where $Q_{N}($.$) is the distribution function of the maximal investor's \rho$ (the $N^{t h}$ order statistic of $\rho$ ) and $q_{N}($.$) is its density function. The first term in (16) gives the expected value of$ the firm if it remains public. This occurs when the maximal investor's $\rho$ is less than $\widehat{\rho}(N)$, the probability of which is $Q_{N}(\widehat{\rho}(N))$. The stock price of the firm when it remains public is given by $W_{p u b}^{I}(N)$. The second and third terms give the expected value of the firm when it goes private. The firm goes private whenever the maximal investor's $\rho>\hat{\rho}$. This occurs with probability $1-Q_{N}(\widehat{\rho}(N))$. When the firm goes private, the price at which the public investors will be able to sell their shares to the private investor is $\gamma W_{p r}^{I}(\rho)+[1-\gamma] W_{p u b}^{I}(N)$. The cutoff $\widehat{\rho}(N)$, such that the manager is indifferent between private and public ownership when the maximal investor's $\rho=\widehat{\rho}$ is given by the following equality (Proposition 3):

$$
\widehat{\rho}=\bar{\rho}+\frac{L}{\delta\left[X_{h}-X_{l}\right]}
$$

We now have the following lemma.

Lemma 7 For all values of going-private surplus accruing to the public shareholders, $\gamma \in$ $\left[0, \gamma^{*}\right]$, the expected stock price at $t=0, E\left(P_{0}(N)\right)$, is increasing in the level of investor participation, $N$.

An increase in $N$ has several effects. An increase in $N$ increases the stock price with public ownership, the probability that the firm will have public ownership and also the expected value

the firm's shares will be held by the investor with the maximal level of agreement with the manager. The share price at any date prior to $t=3$ depends only on the level of agreement of the maximal investor at $t=3$. Thus, the stock price at $t=0$ is independent of the level of agreement of the shareholder at $t=0$ (since this shareholder will sell at $t=2$ and not remain as an investor when the project decision is made), and our model does not put any restriction on the shareholding pattern of the firm with public ownership prior to $t=3$. 
of the firm with private ownership. The above lemma shows that when $\gamma$ is in the interval $\left[0, \gamma^{*}\right]$, the cumulative effect of an increase in $N$ is to increase the expected stock price at $t=0$. The restriction on $\gamma$ is necessary because an increase in the probability of the firm staying public leads to a decreases in the expected stock price at $t=0$. This occurs because the expected value of the firm with private ownership is greater than the expected stock price with public ownership (Proposition 4). The restriction on $\gamma$ ensures that this effect does not dominate. In the following analysis we assume $\gamma \in\left[0, \gamma^{*}\right]$.

Given the expected price at $t=0$, individual investors take a decision to participate in the IPO by comparing their expected profits due to the difference between the IPO price and the expected price at $t=0$, with their cost of participation. The number of investors who participate in the IPO is determined by the participation condition of the marginal investor. The expected profits for an individual investor can be given as $\frac{E\left(P_{0}(N)\right)-P}{N}$, where $P$ is the price of the IPO. The $N$ in the denominator reflects the pro rata allocation of shares to the individual investors. ${ }^{36}$ When $N$ investors participate in the IPO, the marginal investor's cost of participation is $F^{-1}\left(\frac{N}{\bar{N}}\right)$. In equilibrium, the marginal investor will be indifferent between participating and not participating in the IPO. The firm thus indirectly chooses the level of investor participation by setting the price of the IPO to maximize the proceeds subject to the participation constraint of the marginal investor. The firm's problem can be written as:

$$
\begin{array}{ll}
\max _{N} & P \\
\text { s.t. } & \frac{E\left(P_{0}(N)\right)-P}{N}=F^{-1}\left(\frac{N}{\bar{N}}\right) \quad \text { and } \quad 0 \leq N
\end{array}
$$

Substituting the investor's participation constraint into the firm's objective we get

$$
\begin{array}{cl}
\max _{N} & E\left(P_{0}(N)\right)-N F^{-1}\left(\frac{N}{\bar{N}}\right) \\
\text { s.t. } & 0 \leq N
\end{array}
$$

The tradeoff facing the firm in choosing $N$ through its choice of the IPO price is as follows. On the one hand, an increase in $N$ increases the expected price at $t=0$ (Lemma 7 ). On the other hand, an increase in $N$ reduces the number of shares each investor gets and increases the trading cost of the marginal investor. The IPO price trades off the above benefit and cost. Let $N^{*}$ denote the optimal level of investor participation in equilibrium. ${ }^{37}$ The following proposition collects comparative statics properties of the equilibrium.

\footnotetext{
${ }^{36} \mathrm{As}$ is evident, our analysis will remain the same if all the shares are allocated randomly to one of the participating investors. In this case the probability of getting all the shares for an individual investor will be $\frac{1}{N}$.

${ }^{37}$ This problem can potentially have multiple solutions. The proof of Proposition 6 in the Appendix provides the sufficiency condition for a unique equilibrium solution.
} 
Proposition 6 Assuming that the sufficiency condition for a unique interior $N^{*}>0$ is satisfied, the equilibrium level of investor participation, $N^{*}$, is increasing in the extent of managerial ownership, $\alpha$, the cash flow from the good project, $X_{h}$, and the probability $\delta$ of the manager drawing a prior belief of $\theta_{h} . N^{*}$ is decreasing in the cost of managerial effort, $\beta$. The degree of underpricing in equilibrium is, $E\left(P_{0}\left(N^{*}\right)\right)-P^{*}$, where $P^{*}$ is the equilibrium IPO price. Moreover, $N^{*}$ is increasing in $E\left(P_{0}\left(N^{*}\right)\right)-P^{*}$.

An increase in $N^{*}$ increases $\bar{\rho}$ and $\eta_{p u b}^{*}$. Thus, the firm chooses a larger $N^{*}$ when managerial autonomy is more important, say when the manager has greater ownership and when the restructuring project is more valuable for the manager. There is also a one-to-one correspondence between the extent of underpricing and the level of investor participation in equilibrium. Greater underpricing induces greater investor participation. Thus, our model predicts that IPO underpricing is more likely in firms that are higher-valued and those in which owner-managers have higher ownership shares. This is the exact opposite of the prediction one would get from a model in which an owner-manager is trading off some benefit of underpricing against the cost of being personally diluted. An owner-manager in a more valuable firm would perceive a greater cost to being diluted through underpricing and would therefore be expected to underprice less.

While it is well known that IPOs are consistently underpriced (e.g. Ritter and Welch (2002)) and various theories have been proposed for why (see Ljungqvist (forthcoming) for a survey), our analysis highlights a simple and previously-unexplored intuitive advantage of underpricing. IPO underpricing attracts more investors and has a desirable impact on the post-IPO trading price, raising its expected level and lowering its volatility. ${ }^{38}$ This, in turn, gives the manager more autonomy.

\subsection{Empirical Predictions}

We discuss the main empirical predictions of our model. For the most part, these are novel predictions that have yet to be tested. The key to testing these predictions will be to come up with reasonable empirical proxies for the agreement parameter $\rho$ and the autonomy parameter $\eta$. Proxies for $\rho$ may be proxy fights (the fewer of them the higher the inferred $\rho$ ), shareholder reactions to major investments in $\mathrm{R} \& \mathrm{D}$, advertising and acquisitions (the higher the announce-

\footnotetext{
${ }^{38}$ To the extent that our analysis implies that underpricing increases investor participation in the IPO, it is similar to Rock's (1986) rationale for underpricing which relies on the argument that underpricing makes the participation of uninformed investors possible. What is novel about our explanation is that this greater investor participation is desired by the firm not to enhance the success of the IPO itself (as in Rock (1986)), but rather to alter the dynamics of the post-IPO stock price and to endow the manager with greater control.
} 
ment effect, the higher the inferred $\rho$ ), and the dual-class control premium (the higher this premium, the lower the inferred $\rho$ ). Proxies for $\eta$ may be provisions in IPO charters, and relevant variables in the Gompers, Ishi and Metrick (2003) governance index.

1. The greater the investor participation for a publicly-traded firm, the lower should be the stringency of corporate governance for the firm. This prediction follows from Proposition 1. If we view better-known and larger firms as having greater investor participation, then this prediction is consistent with Gompers, Ishi and Metrick (2003) that managers in larger firms have greater protection from takeovers, assuming that greater protection signifies more managerial autonomy. However, this evidence may be viewed as being a bit tangential, and one would need to more directly test this prediction by using other proxies for investor participation, such as the number of analysts following the firm.

2. A public firm will go private when its stock price is sufficiently low and/or the volatility of this price is sufficiently high. This follows from Proposition 3. This prediction is consistent with the anecdotal evidence presented in the Introduction, but we are not aware of any large-sample empirical evidence about it.

3. The probability of a going-private transaction declines as the liquidity cost of private ownership increases. This follows from Proposition 3. One way to test this prediction would be to compare going-private transactions across markets or countries with private equity markets with varying levels of liquidity.

4. A public firm that goes private will exhibit improved performance after going private and be worth more. This result follows from Lemma 6 .

5. A going-private transaction will occur only at a price that represents a substantial premium above the firm's pre-transaction stock price. This follows from Proposition 3.

6. Ceteris paribus the higher the price paid to take the firm private the less stringent is the corporate governance put in place (the greater is the autonomy given to the manager) after the firm is taken private. This follows from Lemma 4, which shows that $\eta^{*}$ with private ownership is increasing in $\rho_{p r}$, and from the fact that the higher is $\rho_{p r}$ the higher is the private investor's valuation of the firm.

7. Higher investor participation leads to younger firms going public (Proposition 5).

8. IPO underpricing is more likely in more highly-valued firms in which managers hold more of the firm's equity, and leads to less restrictive IPO charters that provide managers greater autonomy. This follows from Proposition 6 . 


\section{CONCLUSION}

The development of liquid capital markets for publicly-traded firms is one of the most noteworthy features of industrialized economies. This liquidity has an obvious advantage for public firms in that it lowers the firm's cost of capital. ${ }^{39}$ While this advantage also appears in our analysis, we show that public-market liquidity also has a surprising dark side which manifests itself in volatility in the firm's ownership base and hence uncertainty about the degree of alignment between the manager and shareholders. That is, the liquidity of public ownership is both its blessing and its curse.

We also show that greater public-market investor participation strengthens the incentives for firms to stay public. This works via two channels. First, higher investor participation leads to a higher valuation for the marginal investor holding the stock. And second, the (crosssectional) variance of the valuations of investors holding the firm's stock is smaller when there are more investors. Both effects work in concert and raise the firm's stock price by increasing the expected degree of agreement between the manager and shareholders. That is, greater investor participation in the public equity market also encourages greater firm participation.

A central feature of our analysis is that the firm's ownership mode determines the three key factors - corporate governance, liquidity and the stability of the firm's shareholder base that influence the firm's decision of whether to be public or private. As part of our analysis, we provide an approach for endogenously determining both security benefits and the allocation of control between the manager and investors, in a setting in which the manager has no innate preference for control via exogenous private benefits of control. We show how this determination differs across private and public ownership due to the inherently greater liquidity of the latter. Moreover, our major results are unlikely to obtain with asymmetric pre-contract information or exogenous private control benefits. We believe our approach can be fruitfully used to address other issues in the theory of the firm, such as the boundaries of the firm and the interaction between firm boundaries and its choice of ownership mode.

\footnotetext{
${ }^{39} \mathrm{An}$ aspect of this liquidity that we have not emphasized is that the shareholder base can also become misaligned because the firm's business changes, say from paint to plastics. Liquidity permits shareholders to relatively easily sell their shares to another group that may be more aligned with the new strategy.
} 


\section{A APPENDIX A}

\section{A.1 Proof of Lemma 1}

Since $V_{p u b}^{M}$ is concave in $e$ the first-order condition (FOC) is necessary and sufficient for the unique maximum. The optimal effort level $e_{p u b}^{*}$ is determined through the FOC as:

$$
\begin{gathered}
\delta\left[\bar{\rho}+[1-\bar{\rho}] \eta_{p u b}\right]\left[\alpha\left[X_{h}-S\right]-\Psi\right]-\beta e=0 \quad \text { which yields } \\
e_{p u b}^{*}=\frac{\delta}{\beta}\left[\bar{\rho}+[1-\bar{\rho}] \eta_{p u b}\right]\left[\alpha\left[X_{h}-S\right]-\Psi\right]
\end{gathered}
$$

It is now clear that $\frac{\partial e_{p u b}^{*}}{\partial \bar{\rho}}>0, \frac{\partial e_{p u b}^{*}}{\partial \alpha}>0, \frac{\partial e_{p u b}^{*}}{\partial \eta_{p u b}}>0$ and $\frac{\partial e_{p u b}^{*}}{\partial \beta}<0$.

Q.E.D.

\section{A.2 Proof of Lemma 2}

The distribution function of $\rho_{N}, Q\left(\rho_{N}\right)$ can be given as $Q\left(\rho_{N}\right)=G^{N}(\rho)$ where $G(\rho)$ represents the distribution function of $\rho$. Since $G(\rho) \leq 1$, it is clear that for any two values of $N$, say $N_{1}$ and $N_{2}$ with $N_{1}<N_{2}, Q\left(\rho_{N_{2}}\right)$ first order stochastic dominates $Q\left(\rho_{N_{1}}\right)$. This in turn implies $\overline{\rho_{N_{2}}}<\overline{\rho_{N_{1}}}$. Thus we have proved the first part of the lemma.

To prove the second part of the lemma, we first note that $\rho_{N}$ has the following asymptotically degenerate distribution with 0 variance:

$$
F\left(\rho_{N}\right)= \begin{cases}1 & \rho_{N}=1 \\ 0 & \rho_{N} \neq 1\end{cases}
$$

Thus, asymptotically $\rho_{N}$ has 0 variance. To show that for finite $N$ the variance of $\rho_{N}$ is decreasing in $N$, we can use an approximate inverse Taylor series expansion of the expression of the variance of $\rho_{N}$. That is, the variance of $\rho_{N}$ is given as $\operatorname{Var}\left(\rho_{N}\right)=E\left(\rho_{N}^{2}\right)-E\left(\rho_{N}\right)^{2}$, where

$$
E\left(\rho_{N}\right)=\int_{0}^{1} G(\rho)^{N-1} g(\rho) \rho d(\rho)
$$

We know from the probability integral transformation that $G\left(\rho_{N}\right)=u_{N}$, where $u_{N}$ is the $N^{\text {th }}$ order statistic from a uniform distribution. Thus, we can express any function of the $N^{\text {th }}$ order statistic of any continuous distribution as a function of the $N^{t h}$ order statistic of the uniform distribution. Using this and performing a Taylor series expansion of the variance of $\rho_{N}$, a good approximation for $\operatorname{Var}\left(\rho_{N}\right)$ can be written as follows:

$$
\operatorname{Var}\left(\rho_{N}\right) \approx \frac{N}{[N+1]^{2}[N+2]}\left\{g\left[G^{-1}\left(\frac{1}{N+1}\right)\right]\right\}^{-2}
$$

For a detailed derivation of the above expression, see Gibbons (1971). The above expression shows the conditions under which $\operatorname{Var}\left(\rho_{N}\right)$ is decreasing in $N$. We note that $G^{-1}\left(\frac{1}{N+1}\right)$ is decreasing in $N$. It is difficult to say much about $\left\{g\left[G^{-1}\left(\frac{1}{N+1}\right)\right]\right\}^{-2}$, unless we know the shape of the distribution. The condition required for $\operatorname{Var}\left(\rho_{N}\right)$ to decrease in $N$ is that $T(N) \equiv\left\{g\left[G^{-1}\left(\frac{1}{N+1}\right)\right]\right\}^{-2}$ should not increase with $N$ at an order of magnitude greater than rate at which $\frac{N}{[N+1]^{2}[N+2]}$ decreases with $N \cdot \frac{N}{[N+1]^{2}[N+2]}$ decreases at an order of magnitude equal to $N^{2}$. Thus, the condition required is that $\left\{g\left[G^{-1}\left(\frac{1}{N+1}\right)\right]\right\}^{-2}$ should not increase at an order of magnitude greater than $N^{2}$. This is clearly true when $T(N)$ is non-increasing in $N$. Q.E.D.

\section{A.3 Proof of Lemma 3}

The public market governance regime is fixed so as to maximize the $t=0$ stock price of the firm. The stock price at $t=0$ is given by (5). Since $V_{p u b}^{I}$ is concave in $\eta_{p u b}$, the first-order condition (FOC) is necessary and 
sufficient for a unique maximum. We can write $V_{p u b}^{I}$ as:

$$
\begin{aligned}
V_{p u b}^{I} & =[1-\alpha]\left[e_{p u b}^{*} \delta\left[\bar{\rho}\left\{X_{h}-S\right\}+[1-\bar{\rho}] \eta_{p u b}\left\{X_{l}-S\right\}\right]+S\right] \\
& =[1-\alpha]\left[\frac{\delta}{\beta}\left[\bar{\rho}+\{1-\bar{\rho}\} \eta_{p u b}\right]\left[\alpha\left[X_{h}-S\right]-\Psi\right] \delta\left[\bar{\rho}\left\{X_{h}-S\right\}+[1-\bar{\rho}] \eta_{p u b}\left\{X_{l}-S\right\}\right]+S\right]
\end{aligned}
$$

Differentiating with respect to $\eta_{p u b}$ we get the first-order condition:

$$
\begin{aligned}
\frac{\partial V_{p u b}^{I}}{\partial \eta_{p u b}}= & {[1-\alpha]\left[\frac{\delta}{\beta}[1-\bar{\rho}]\left[\alpha\left\{X_{h}-S\right\}-\Psi\right] \delta\left[\bar{\rho}\left\{X_{h}-S\right\}+\{1-\bar{\rho}\} \eta_{p u b}^{*}\left\{X_{l}-S\right\}\right]\right.} \\
& +[1-\alpha]\left[\frac{\delta}{\beta}\left[\bar{\rho}+\{1-\bar{\rho}\} \eta_{p u b}^{*}\right]\left[\alpha\left[X_{h}-S\right]-\Psi\right] \delta[1-\bar{\rho}]\left[X_{l}-S\right]=0\right. \\
\text { Simplifying we have } \quad & \bar{\rho}\left[X_{h}-S\right]+[1-\bar{\rho}] \eta_{p u b}^{*}\left[X_{l}-S\right]+\left[\bar{\rho}+\{1-\bar{\rho}\} \eta_{p u b}^{*}\right]\left[X_{l}-S\right]=0 \\
\text { Or } \quad & \eta_{p u b}^{*}=\frac{\bar{\rho}\left[X_{h}+X_{l}-2 S\right]}{2[1-\bar{\rho}]\left[S-X_{l}\right]}
\end{aligned}
$$

A sufficient condition for $\eta_{p u b}^{*}<1$ is:

$$
\frac{\rho_{h}\left[X_{h}+X_{l}-2 S\right]}{2\left[1-\rho_{h}\right]\left[S-X_{l}\right]}<1
$$

In the following analysis, we assume that the above condition is satisfied.

To verify the second order condition is satisfied we can differentiate $\frac{\partial V_{p u b}^{I}}{\partial \eta}$ with respect to $\eta$ to get

$$
\begin{aligned}
\frac{\partial^{2} V_{p u b}^{I}}{\partial \eta_{p u b}^{2}}= & {[1-\alpha]\left[\frac{\delta}{\beta}[1-\bar{\rho}]\left[\alpha\left\{X_{h}-S\right\}-\Psi\right] \delta\{1-\bar{\rho}\}\left\{X_{l}-S\right\}\right] } \\
& +[1-\alpha]\left[\frac{\delta}{\beta}\{1-\bar{\rho}\}\left[\alpha\left[X_{h}-S\right]-\Psi\right] \delta[1-\bar{\rho}]\left[X_{l}-S\right]\right.
\end{aligned}
$$

Since $X_{l}<S$, it is obvious that the right hand side of the above expression is negative. From (A-5) it is also clear that $\frac{\partial \eta_{p u b}^{*}}{\partial \bar{\rho}}>0, \frac{\partial \eta_{p u b}^{*}}{\partial X_{h}}>0$ and $\frac{\partial \eta_{p u b}^{*}}{\partial X_{l}}>0$.

Q.E.D.

\section{A.4 Proof of Proposition 1}

This is obvious from Lemma 2 and Lemma 3.

Q.E.D.

\section{A.5 Proof of Proposition 2}

Note that $\frac{\partial V_{p u b}^{M}}{\partial N}=\left[\frac{\partial V_{p u b}^{M}}{\partial \bar{\rho}} \cdot \frac{\partial \bar{\rho}}{\partial N}\right]+\left[\frac{\partial V_{p u b}^{M}}{\partial \eta_{p u b}^{*}} \cdot \frac{\partial \eta_{p u b}^{*}}{\partial N}\right]$. Clearly $\frac{\partial V_{p u b}^{M}}{\partial \bar{\rho}}>0$. From Lemma 2 we know $\frac{\partial \bar{\rho}}{\partial N}>0$. Moreover $\frac{\partial V_{p u b}^{M}}{\partial \eta_{p u b}^{*}}>0($ see $(2))$ and $\frac{\partial \eta_{p u b}^{*}}{\partial N}>0($ see Proposition 1$)$.

Q.E.D.

\section{A.6 Proof of Lemma 4}

The managerial autonomy parameter with private ownership is fixed so as to maximize the valuation of the private investor. The valuation of the private investor at $t=0$ is given by (13). Since $V_{p r}^{I}$ is concave in $\eta$, the first-order condition (FOC) is necessary and sufficient for a unique maximum. We can write $V_{p r}^{I}$ as:

$$
\begin{aligned}
V_{p r}^{I} & =[1-\alpha]\left\{e_{p r}^{*}\left[\delta \rho_{p r}\left[X_{h}-S-L\right]+\delta\left[1-\rho_{p r}\right] \eta_{p r}\left[X_{l}-S-L\right]-\left[1-\delta\left\{\rho_{p r}+\left[1-\rho_{p r}\right] \eta_{p r}\right\} L\right]\right]+S\right\} \\
& =[1-\alpha]\left\{\frac{\delta}{\beta}\left\{\rho_{p r}+\left[1-\rho_{p r}\right] \eta_{p r}\right\}\left[\alpha\left\{X_{h}-S\right\}-\Psi\right]\left[\delta \rho_{p r}\left[X_{h}-S\right]+\delta\left[1-\rho_{p r}\right] \eta_{p r}\left[X_{l}-S\right]-L\right]+S\right\}
\end{aligned}
$$


Differentiating with respect to $\eta$ we get

$$
\begin{aligned}
\frac{\partial V_{p r}^{I}}{\partial \eta_{p r}}= & {[1-\alpha]\left\{\frac{\delta}{\beta}\left[1-\rho_{p r}\right]\left[\alpha\left\{X_{h}-S\right\}-\Psi\right]\left[\delta \rho_{p r}\left[X_{h}-S\right]+\delta\left[1-\rho_{p r}\right] \eta_{p r}^{*}\left[X_{l}-S\right]-L\right]+S\right\} } \\
& +[1-\alpha]\left[\frac{\delta}{\beta}\left\{\rho_{p r}+\left[1-\rho_{p r}\right] \eta_{p r}^{*}\right\}\left[\alpha\left\{X_{h}-S\right\}-\Psi\right] \delta\left[1-\rho_{p r}\right]\left[X_{l}-S\right]\right]=0 \\
\text { Simplifying we have } \quad & \delta \rho_{p r}\left[X_{h}-S\right]+\delta\left[1-\rho_{p r}\right] \eta_{p r}^{*}\left[X_{l}-S\right]-L+\delta\left[\rho_{p r}+\left[1-\rho_{p r}\right] \eta_{p r}^{*}\right]\left[X_{l}-S\right]=0 \\
\text { which implies } \quad & \eta_{p r}^{*}=\frac{\delta \rho_{p r}\left[X_{h}+X_{l}-2 S\right]-L}{2 \delta\left[1-\rho_{p r}\right]\left[S-X_{l}\right]}
\end{aligned}
$$

Verification of the satisfaction of the second-order condition, $\frac{\partial^{2} V_{p r}^{I}}{\partial \eta_{p r}^{2}}<0$, is along the same lines as in the proof of Lemma 3.

Q.E.D.

\section{A.7 Proof of Lemma 5}

The optimal control allocation divides control between the manager and the investors. Hence, two kinds of renegotiation can occur: the investor can acquire additional control from the manager, or the manager can acquire additional control from the investor, with the acquisition of additional control in each case involving an offer to increase the other party's ownership share; the party acquiring control ends up with total control. We consider each kind of renegotiation. It is convenient to define $\alpha_{1} \equiv \frac{S-X_{l}}{X_{h}-X_{l}}$ and $\alpha_{2} \equiv \frac{X_{h}\left[S-X_{l}\right]}{X_{h}-X_{l}}$.

\section{Investor Acquiring Control from Manager}

Starting out with $\eta_{p r}^{*}$, the expected loss suffered by the investor in the event of disagreement is Loss = $\eta_{p r}^{*}[1-\alpha]\left[S-X_{l}\right]$, and the expected benefit enjoyed by the manager is Bene $f i t=\alpha \eta_{p r}^{*}\left[X_{h}-S\right]$. For renegotiation to fail, the loss suffered by the investor should be less than the benefit perceived by the manager. That is

$$
\begin{aligned}
\eta_{p r}^{*}[1-\alpha]\left[S-X_{l}\right] & <\alpha \eta_{p r}^{*}\left[X_{h}-S\right], \\
\text { which implies } \quad \alpha & >\frac{S-X_{l}}{X_{h}-X_{l}}
\end{aligned}
$$

\section{Manager Acquiring Control from the Investor}

The manager can acquire total control by agreeing to reduce his ownership stake from $\alpha$ to some $\alpha_{0}<\alpha$. The manager's expected utility with the original contract is $\alpha\left\{\eta_{p r}^{*} X_{h}+\left[1-\eta_{p r}^{*}\right] S\right\}$. If he acquires total control, he can guarantee investment with probability 1 , and his utility is $\alpha_{0} X_{h}$. So a necessary condition for the manager to be willing to renegotiate is

$$
\begin{aligned}
\alpha_{0} X_{h} & \geq \alpha\left\{\eta_{p r}^{*} X_{h}+\left[1-\eta_{p r}^{*}\right] S\right\}, \quad \text { which implies } \\
\alpha_{0} & \geq \frac{\alpha\left[\eta_{p r}^{*} X_{h}+\left[1-\eta_{p r}^{*}\right] S\right]}{X_{h}} \equiv \hat{\hat{\alpha}}
\end{aligned}
$$

The investor's expected utility is $[1-\alpha]\left[\eta_{p r}^{*} X_{l}+\left\{1-\eta_{p r}^{*}\right\} S\right]$ without renegotiation, and it is $\left[1-\alpha_{0}\right] X_{l}$ with renegotiation. Thus, for the investor to be willing to renegotiate we need

$$
\begin{aligned}
{\left[1-\alpha_{0}\right] X_{l} } & \geq[1-\alpha]\left[\eta_{p r}^{*} X_{l}+\left\{1-\eta_{p r}^{*}\right\} S\right], \quad \text { which implies } \\
\alpha_{0} & \leq 1-\frac{[1-\alpha]\left[\eta_{p r}^{*} X_{l}+\left\{1-\eta_{p r}^{*}\right\} S\right]}{X_{l}} \equiv \hat{\alpha}
\end{aligned}
$$

For renegotiation to be feasible, we need $[\hat{\hat{\alpha}}, \hat{\alpha}]$ to be a nonempty set, i.e. $\hat{\alpha}>\hat{\hat{\alpha}}$. Thus, renegotiation proofness is guaranteed if

$$
\hat{\alpha}<\hat{\hat{\alpha}}
$$


Substituting for $\hat{\alpha}$ and $\hat{\hat{\alpha}}$ in (A-11) means that the following is sufficient for renegotiation-proofness:

$$
\begin{aligned}
1-\frac{[1-\alpha]\left[\eta_{p r}^{*} X_{l}+\left\{1-\eta_{p r}^{*}\right\} S\right]}{X_{l}} & <\frac{\alpha\left[\eta_{p r}^{*} X_{h}+\left[1-\eta_{p r}^{*}\right] S\right]}{X_{h}}, \quad \text { which implies } \\
\alpha\left\{\frac{\eta_{p r}^{*} X_{h}+\left[1-\eta_{p r}^{*}\right] S}{X_{h}}-\frac{\eta_{p r}^{*} X_{l}+\left[1-\eta_{p r}^{*}\right] S}{X_{l}}\right\} & >1-\frac{\eta_{p r}^{*} X_{l}+\left[1-\eta_{p r}^{*}\right] S}{X_{l}}
\end{aligned}
$$

The above inequality can be further simplified as:

$$
\alpha \frac{S\left\{X_{l}-X_{h}\right\}\left\{1-\eta_{p r}^{*}\right\}}{X_{l} X_{h}}>\frac{\left\{1-\eta_{p r}^{*}\right\}\left\{X_{l}-S\right\}}{X_{l}}
$$

Noting that $X_{l}<S<X_{h}$, the following suffices for (A-12) to hold:

$$
\alpha<\frac{X_{h}\left[S-X_{l}\right]}{X_{h}-X_{l}}
$$

Combining (A-8) and (A-13), we see that renegotiation-proofness obtains if

$$
\alpha \in\left(\frac{S-X_{l}}{X_{h}-X_{l}}, \frac{X_{h}\left[S-X_{l}\right]}{X_{h}-X_{l}}\right)
$$

Q.E.D.

\section{A.8 Proof of Proposition 3}

The manager will strictly prefer private ownership whenever $V_{p r}^{M}>V_{p u b}^{M}$. i.e.

$$
\begin{aligned}
\frac{\beta}{2}\left\{\frac{\delta\left[\delta \rho_{p r}\left[X_{h}-X_{l}\right]-L\right]\left[\alpha\left[X_{h}-S\right]-\Psi\right]}{2 \beta \delta\left[S-X_{l}\right]}\right\}^{2}+\alpha S & >\frac{\beta}{2}\left\{\frac{\delta \bar{\rho}\left[X_{h}-X_{l}\right]\left[\alpha\left[X_{h}-S\right]-\Psi\right]}{2 \beta\left[S-X_{l}\right]}\right\}^{2}+\alpha S \\
\text { or } \quad \rho_{p r}\left[X_{h}-X_{l}\right]-\frac{L}{\delta} & >\bar{\rho}\left[X_{h}-X_{l}\right] \\
\text { or } \quad \rho_{p r} & >\bar{\rho}+\frac{L}{\delta\left[X_{h}-X_{l}\right]} \equiv \widehat{\rho}
\end{aligned}
$$

It is clear that $\widehat{\rho}$ is increasing in $\bar{\rho}$ and $L$. Further, since $\bar{\rho}$ is increasing in $N$ (Lemma 3), $\widehat{\rho}$ is also increasing in $N$.

Q.E.D.

\section{A.9 Proof of Lemma 6}

The manager's payoff with public ownership is given by (4). The manager's payoff with private ownership can similarly be written as:

$$
\begin{aligned}
V_{p r}^{M} & =\alpha\left\{e_{p r}^{*} \delta \rho_{p r}\left[X_{h}-S\right]+e_{p r}^{*} \delta\left[1-\rho_{p r}\right] \eta_{p r}^{*}\left[X_{h}-S\right]+S\right\}-e_{p r}^{*} \delta\left[\rho_{p r}+\left\{1-\rho_{p r}\right\} \eta_{p r}^{*}\right] \Psi-\frac{\beta e_{p r}^{* 2}}{2} \\
& =e_{p r}^{*} \delta\left\{\left[\rho_{p r}+\left\{1-\rho_{p r}\right\} \eta_{p r}^{*}\right]\left[\alpha\left\{X_{h}-S\right\}-\Psi\right]\right\}+\alpha S-\frac{\beta e_{p r}^{* 2}}{2}
\end{aligned}
$$

Substituting for $e_{p r}^{*}$ from (12) into (A-15):

$$
\begin{aligned}
V_{p r}^{M} & =\beta e_{p r}^{* 2}+\alpha S-\frac{\beta e_{p r}^{* 2}}{2} \\
& =\frac{\beta e_{p r}^{* 2}}{2}+\alpha S
\end{aligned}
$$

Comparing (4) and (A-16), it is apparent that whenever the manager prefers private ownership, that is when $V_{p r}^{M}>V_{p u b}^{M}$, the search effort with private ownership, $e_{p r}^{*}$, is greater than that with public ownership, $e_{p u b}^{*}$. Q.E.D. 


\section{A.10 Proof of Proposition 4}

The stock price that will prevail at $t=0$, when the firm has public ownership, is given by (5). Comparing (5) and (13) we see that a private investor will be able to purchase shares if and only if:

$$
\begin{aligned}
W_{p r}^{I} \geq & W_{p u b}^{I} \\
\quad \text { or } & e_{p r}^{*}\left[\delta \rho_{p r}\left[X_{h}-S-L\right]+\delta\left[1-\rho_{p r}\right] \eta_{p r}\left[X_{l}-S-L\right]-\left[1-\delta\left\{\rho_{p r}+\left[1-\rho_{p r}\right] \eta_{p r}\right\} L\right]\right]+S \\
\geq & e_{p u b}^{*} \delta\left[\bar{\rho}\left\{X_{h}-S\right\}+[1-\bar{\rho}] \eta_{p u b}^{*}\left\{X_{l}-S\right\}\right]+S
\end{aligned}
$$

Substituting for $e_{p r}^{*}, \eta_{p r}^{*}, e_{p u b}^{*}$ and $\eta_{p u b}^{*}$ and simplifying we have:

$$
\begin{aligned}
{\left[\frac{\delta\left[\delta \rho_{p r}\left[X_{h}-X_{l}\right]-L\right]\left[\alpha\left[X_{h}-S\right]-\Psi\right]}{2 \beta \delta\left[S-X_{l}\right]}\right]\left[\frac{\delta \rho_{p r}\left[X_{h}-X_{l}\right]-L}{2}\right] } & \geq\left[\frac{\delta \bar{\rho}\left[X_{h}-X_{l}\right]\left[\alpha\left[X_{h}-S\right]-\Psi\right]}{2 \beta\left[S-X_{l}\right]}\right]\left[\frac{\delta \bar{\rho}\left[X_{h}-X_{l}\right]}{2}\right] \\
\text { simplifying we have }\left[\delta \rho_{p r}\left[X_{h}-X_{l}\right]-L\right]^{2} & \geq \delta^{2} \bar{\rho}^{2}\left[X_{h}-X_{l}\right]^{2} \\
\text { which implies } \rho_{p r} & \geq \bar{\rho}+\frac{L}{\delta\left[X_{h}-X_{l}\right]}
\end{aligned}
$$

Comparing (A-17) to (A-14) we see that they are the same. Thus, whenever the manager prefers private ownership, the share price with private ownership will be greater than the share price with public ownership. Q.E.D.

\section{A.11 Proof of Proposition 5}

As discussed in the text, we have $\frac{\partial G(\rho)}{\partial a}<0$. An immediate implication of this is that ceteris paribus the expected agreement parameter in the public market is increasing in firm age, that is $\frac{\partial \bar{\rho}(a)}{\partial a}>0$. A manager chooses between public and private ownership by comparing $V_{p u b}^{M}$ and $V_{p r}^{M}$. From the proof of Proposition 3 we know that the manager will prefer public ownership whenever the following inequality is satisfied.

$$
\bar{\rho}(a)>\rho_{p r}-\frac{L}{\delta\left[X_{h}-X_{l}\right]}
$$

Given $\frac{\partial \bar{\rho}(a)}{\partial a}>0$, the last inequality implies that the manager will choose public ownership whenever the firm age is greater than $a^{*}$, where $a^{*}$ can be given as

$$
a^{*}=\bar{\rho}^{-1}\left(\rho_{p r}-\frac{L}{\delta\left[X_{h}-X_{l}\right]}\right)
$$

So, we have (rewriting (A-18)):

$$
\bar{\rho}\left(a^{*}(N), N\right)=\rho_{p r}-\frac{L}{\delta\left[X_{h}-X_{l}\right]}
$$

Note that $\frac{\partial a^{*}}{\partial N}=-\frac{\frac{\partial \bar{\rho}}{\partial N}}{\frac{\partial \bar{\rho}}{\partial a^{*}}}$, where $\frac{\partial \bar{\rho}}{\partial N}>0$ (Lemma 3) and $\frac{\partial \bar{\rho}}{\partial a^{*}}>0$ (see above). Thus $\frac{\partial a^{*}}{\partial N}<0$. Q.E.D.

\section{A.12 Proof of Lemma 7}

Differentiating $E\left(P_{0}(N)\right.$ with respect to $N$ we have

$$
\begin{aligned}
\frac{\partial E\left(P_{0}(N)\right)}{\partial N}= & \frac{\partial Q(\widehat{\rho})}{\partial N}\left[W_{p u b}^{I}-\left\{\gamma E\left(W_{p r}^{I}(\rho) \mid \rho>\widehat{\rho}\right)+[1-\gamma] W_{p u b}^{I}\right\}\right] \\
& +Q(\widehat{\rho}) \frac{\partial \widehat{\rho}}{\partial N}\left[W_{p u b}^{I}-\left\{\gamma E\left(W_{p r}^{I}(\rho) \mid \rho>\widehat{\rho}\right)+[1-\gamma] W_{p u b}^{I}\right\}\right] \\
& +Q(\widehat{\rho}) \frac{\partial W_{p u b}^{I}}{\partial N}+[1-Q(\widehat{\rho})]\left\{\gamma \frac{\partial E\left(W_{p r}^{I}(\rho) \mid \rho>\widehat{\rho}\right)}{\partial N}+[1-\gamma] \frac{\partial W_{p u b}^{I}}{\partial N}\right\}
\end{aligned}
$$


From the proof of Proposition 1 we know that $Q_{N+1}($.$) first-order stochastic dominates Q_{N}($.$) . Thus, \frac{\partial Q(\widehat{\rho})}{\partial N}<0$. From Proposition 4 we also know that the value of the firm when it goes private, $\gamma E .\left(W_{p r}^{I}(\rho) \mid \rho>\widehat{\rho}().\right)+[1-$ $\left.\gamma] W_{p u b}^{I}().\right)$, is strictly greater than its value when it stays public, $W_{p u b}^{I}($.$) . This implies that the first term on$ the right-hand side of (A-19) is positive. Further $E\left(W_{p r}^{I}(\rho) \mid \rho>\widehat{\rho}\right)$ depends on $N$ through $\widehat{\rho}$ and through the dependence of $Q($.$) on N$. From the proof of Proposition 3, we know that $\widehat{\rho}$ is increasing in $\bar{\rho}$ which in turn is increasing in $N$. This, along with the fact that $Q_{N+1}($.$) first-order stochastic dominates Q_{N}($.$) , implies that$ $\frac{\partial E\left(W_{p r}^{I}(\rho) \mid \rho>\widehat{\rho}\right)}{\partial N}>0$. Thus, to prove $\frac{\partial E\left(P_{0}(N)\right)}{\partial N}>0$, it is sufficient to show the following is positive:

$$
Q(\widehat{\rho}) \frac{\partial \widehat{\rho}}{\partial N} \gamma\left[W_{p u b}^{I}-E\left(W_{p r}^{I}(\rho) \mid \rho>\widehat{\rho}\right)\right]+Q(\widehat{\rho}) \frac{\partial W_{p u b}^{I}}{\partial N}+[1-Q(\widehat{\rho})][1-\gamma] \frac{\partial W_{p u b}^{I}}{\partial N}
$$

From the proof of Proposition 3 we know $\widehat{\rho}=\bar{\rho}+\frac{L}{\delta\left[X_{h}-X_{l}\right]}$. Thus, $\frac{\partial \widehat{\rho}}{\partial N}=\frac{\partial \bar{\rho}}{\partial N}$. From the proof of Proposition 4 we can write $W_{p u b}^{I}$ as $K \bar{\rho}^{2}+S$. Where $K \equiv \frac{\delta\left[X_{h}-X_{l}\right]\left[\alpha\left[X_{h}-S\right]-\Psi\right]}{2 \beta\left[S-X_{l}\right]}$. Hence $\frac{\partial W_{p u b}^{I}}{\partial N}$ can be expressed as $\frac{\partial W_{p u b}^{I}}{\partial N}=$ $\frac{2\left[W_{p u b}^{I}-S\right]}{\bar{\rho}} \frac{\partial \bar{\rho}}{\partial N}$. Substituting for $\frac{\partial \widehat{\rho}}{\partial N}$ and $\frac{\partial W_{p u b}^{I}}{\partial N}$ in $(\mathrm{A}-20)$ we have to show

$$
\frac{\partial \bar{\rho}}{\partial N}\left\{Q(\widehat{\rho}) \gamma\left[W_{p u b}^{I}-E\left(W_{p r}^{I}(\rho) \mid \rho>\widehat{\rho}\right)\right]+[Q(\widehat{\rho})+\{1-Q(\widehat{\rho})\}\{1-\gamma\}] \frac{2\left[W_{p u b}^{I}-S\right]}{\bar{\rho}}\right\} \geq 0
$$

From Lemma 3 we know that $\frac{\partial \bar{\rho}}{\partial N}>0$. We also know that $W_{p u b}^{I}>S$. Hence, the above inequality is satisfied for $\gamma=0$, and by continuity it is positive for all $\gamma<\gamma^{*}$, where $\gamma^{*}$ is the value of $\gamma$ for which the above inequality holds as an equality.

Q.E.D.

\section{A.13 Proof of Proposition 6}

The firm chooses $N^{*}$ by equating the marginal benefit, $\frac{\partial E\left(P_{0}(N)\right)}{\partial N}$, to the marginal cost, $\frac{\partial N F^{-1}\left(\frac{N}{\bar{N}}\right)}{\partial N}$. The sufficient conditions for an unique positive interior $N^{*}$ are :

$$
\begin{array}{r}
\frac{\partial E\left(P_{0}(N)\right)}{\partial N}{ }_{N=0}-\frac{\partial N F^{-1}\left(\frac{N}{N}\right)}{\partial N}{ }_{N=0}>0 \\
\text { and } \quad \frac{\partial^{2} E\left(P_{0}(N)\right)}{\partial N^{2}}-\frac{\partial^{2} N F^{-1}\left(\frac{N}{N}\right)}{\partial N^{2}}<0 \quad \forall \quad N>0
\end{array}
$$

Given the above assumption, and since $\frac{\partial N F^{-1}\left(\frac{N}{N}\right)}{\partial N}$ is independent of $i \in\left\{\alpha, X_{h}, \delta, \beta\right\}$ to prove the proposition it is sufficient to show that $\frac{\partial^{2} E\left(P_{0}(N)\right)}{\partial i \partial N}>0$ for $i \in\left\{\alpha, X_{h}, \delta\right\}$ and $\frac{\partial^{2} E\left(P_{0}(N)\right)}{\partial \beta \partial N}<0$. We shall now proceed to do this. Rewriting $E\left(P_{0}(N)\right)$ we have

$$
\begin{aligned}
E\left(P_{0}(N)\right) & =Q_{N}(\widehat{\rho}(N)) W_{p u b}^{I}(N)+\left[1-Q_{N}(\widehat{\rho}(N))\right]\left\{\gamma E_{N}\left(W_{p r}^{I}(\rho) \mid \rho>\widehat{\rho}\right)+[1-\gamma] W_{p u b}^{I}(N)\right\} \\
& =\left[1-\gamma+\gamma Q_{N}(\widehat{\rho}(N)] W_{p u b}^{I}(N)+\gamma \int_{\widehat{\rho}}^{\rho_{h}} W_{p r}^{I} q_{N}(\rho) d \rho\right.
\end{aligned}
$$

In the above expression, $W_{p u b}^{I}$ and $W_{p r}^{I}$ depend on $\alpha$. Differentiating $E\left(P_{0}(N)\right)$ with respect to $\alpha$ we have

$$
\frac{\partial E\left(P_{0}(N)\right)}{\partial \alpha}=\left[1-\gamma+\gamma Q_{N}(\widehat{\rho}(N))\right] \frac{\partial W_{p u b}^{I}}{\partial \alpha}+\gamma \int_{\widehat{\rho}}^{\rho_{h}} \frac{\partial W_{p r}^{I}}{\partial \alpha} q_{N}(\rho) d \rho
$$

To show that $\frac{\partial^{2} E\left(P_{0}(N)\right)}{\partial \alpha \partial N}>0$, we need to show that the right-hand side of $(\mathrm{A}-22)$ is increasing in $N$. That can be done by following the same steps outlined in the proof of Lemma 7. Similarly, we can show that $N^{*}$ is increasing in $\delta$ and $X_{h}$ and decreasing in $\beta$.

The expected stock price after the IPO is given by $E\left(P_{0}\left(N^{*}\right)\right)$. If $P^{*}$ is the IPO price, it is clear that the extent of underpricing is given by $E\left(P_{0}(N)\right)-P^{*}$. We know that in equilibrium the participation constraint of 
the marginal investor will bind. Hence, we have

$$
\begin{aligned}
\frac{E\left(P_{0}\left(N^{*}\right)\right)-P^{*}}{N^{*}} & =F^{-1}\left(\frac{N^{*}}{\bar{N}}\right) \\
\text { or } \quad & E\left(P_{0}\left(N^{*}\right)\right)-P^{*}=N^{*} F^{-1}\left(\frac{N^{*}}{\bar{N}}\right)
\end{aligned}
$$

It is clear that the right-hand side of (A-23) is increasing in $N^{*}$. Thus, $N^{*}$, is increasing in the degree of underpricing $E\left(P_{0}\left(N^{*}\right)\right)-P^{*}$. Q.E.D. 


\section{APPENDIX B}

We now highlight how the manager's share holding can be endogenously determined for either ownership mode. We modify the basic set-up as follows. Project implementation requires a cash investment of $\$ 1$ at $t=3$ and with either ownership mode, the manager raises this through an equity issue at $t=1$. The money is raised from existing shareholders and the managers does not subscribe to the issue. The managerial autonomy parameter $\eta$ is determined at the time of the equity issue at $t=1$. The autonomy parameter is determined so as to minimize the cost of capital. To simplify the analysis we assume that project discovery does not require managerial effort and that the firm gets the project with a probability $p$. The rest of the set-up remains the same as earlier. The modified sequence of events is as follows.

At $t=0$, the manager decides whether to take the firm private or keep it public. If the manager chooses private ownership, the investor who has the maximum valuation for the firm at $t=0$ attempts to take the firm private by buying all the outstanding public shares at $t=0$. After the ownership mode is determined, at $t=1$, the manager raises $\$ 1$ by selling a fraction of the firm's equity to the existing shareholders. The optimal managerial autonomy parameter $\eta$ is also determined at this time. At $t=2$ both the manager and investors learn about project availability. All subsequent events unfold as earlier.

We now solve for the optimal managerial autonomy parameter and the fraction of equity sold to investors to raise financing at $t=1$. We solve the model for public ownership. ${ }^{40}$ Let the manager sell a fraction $\mu_{p u b}$ to raise the financing. The manager's resulting shareholding in the firm will be $\widehat{\alpha}_{p u b}=\alpha\left[1-\mu_{p u b}\right]$. With the modified set-up, the manager's total payoff is

$$
V_{p u b}^{M}=E\left(\widehat{\alpha}_{p u b}\left\{p \delta \rho\left[X_{h}-S-1\right]+p \delta[1-\rho] \eta_{p u b}\left[X_{h}-S-1\right]+S+1\right\}-p \delta\left\{\rho+[1-\rho] \eta_{p u b}\right\} \Psi\right)
$$

The corresponding payoff for the investors who invest in the new issue is

$$
V_{p u b}^{I}=E\left(\mu_{p u b}\left\{p \delta \rho\left[X_{h}-S-1\right]+p \delta[1-\rho] \eta_{p u b}\left[X_{l}-S-1\right]+S+1\right\}\right)
$$

The optimal ownership fraction to be sold $\mu_{p u b}^{*}$ and the optimal managerial autonomy parameter $\eta_{p u b}^{*}$ are determined so as to maximize (A-24) subject to investors breaking even. The manager's problem can be written as

$$
\begin{array}{cl}
\underset{\max _{p u b}, \eta_{p u b}}{\max } & V_{p u b}^{M} \\
\text { s.t. } & V_{\text {pub }}^{I}=1 \quad \text { and } \quad 0 \leq \mu_{\text {pub }} \leq 1,0 \leq \eta_{\text {pub }} \leq 1 .
\end{array}
$$

We now state an assumption that will ensure $\eta_{p u b}^{*} \in(0,1)$ and present the solution to the optimization problem.

\section{Assumption 4}

$$
\begin{aligned}
K & \in\left(1,1-\frac{p \delta[1-\rho]\left[X_{h}-S-1\right]\left[X_{l}-1-S\right]}{t}\right), \\
\text { where } \quad K & \equiv \sqrt{\frac{\left[X_{h}-S-1-\Psi\right]\left[1+S+\left[X_{h}-S-1\right] p \theta \rho\right]}{\left[X_{h}-X_{l}-2 S-2\right]}} \quad \text { and } \\
t & \equiv \sqrt{\left[X_{h}-S-1-\Psi\right]\left[X_{h}-X_{l}-2 S-2\right]\left[1+S+\left[X_{h}-S-1\right] p \theta \rho\right]} .
\end{aligned}
$$

Proposition 7 The unique globally optimal value of managerial autonomy with public ownership, $\eta_{\text {pub }}^{*}$, is

$$
\eta_{p u b}^{*}=\frac{-\left[X_{h}-S-1-\Psi\right]\left[1+S+p \delta \rho\left[X_{h}-S-1\right]\right]+t}{p \delta[1-\rho]\left[X_{h}-S-1\right]\left[X_{l}-1-S\right]} .
$$

The corresponding value of the ownership retained by the manager, $\widehat{\alpha}_{\text {pub }}^{*}$, is given by

$$
\widehat{\alpha_{p u b}^{*}}=\alpha\left[1-\frac{\left[X_{h}-S-1\right]}{t+\Psi p \delta \rho\left[X_{h}-S-1\right]-\left[X_{h}-S-1-\Psi\right][1+S]}\right] .
$$

\footnotetext{
${ }^{40} \mathrm{~A}$ similar analysis can be performed for private ownership. We omit the details for brevity.
} 


\section{REFERENCES}

1. Admati, Anat, Paul Pfleiderer and Josef Zechner (1994), "Large Shareholder Activism, Risk-Sharing, and Financial Market Equilibrium", Journal of Political Economy 102(6), 1097-1130.

2. Aghion, Phillipe and Patrick Bolton (1992), "An Incomplete Contracts Approach to Financial Contracting", The Review of Economic Studies 59(3), 473-494.

3. Aghion, Phillipe and Jean Tirole (1997), "Formal and Real Authority in Organizations", Journal of Political Economy, 105(1), pp. 1-29.

4. Allen, Franklin and Douglas Gale (1999), "Diversity of Opinion and Financing of New Technologies", Journal of Financial Intermediation 8(1-2), 68-89.

5. Baker, Malcolm, and Jeffery Wrugler (2002), "Market Timing and Capital Structure", Journal of Finance 57 (1), 1-32.

6. Bebchuck, Lucian (1999), "The Rent Protection Theory of Corporate Ownership and Control", NBER Working Paper No.W7203.

7. Bennedsen, Morten and Daniel Wolfenzon, (2000) "The balance of power in closely held corporations", Journal of Financial Economics 58, 113-140.

8. Bernardo, Antonio, and Ivo Welch (2001), "On the Evolution of Overconfidence and Entrepreneurs", Journal of Economics and Management Strategy 10 (3), 301-330.

9. Bhattacharya, Sudipto and Giovanna Nicodano (2001), "Insider Trading, Investment and Liqudiity: A Welfare Analysis", The Journal of Finance, 56(3), 1141-1156.

10. Bhide, Amar (1993), "The Hidden Costs of Stock Market Liquidity", Journal of Financial Economics 34 (1), 31-51.

11. Black, Bernard, S. and Ronald. J. Gilson (1998), "Venture capital and the structure of capital markets: banks versus stock markets", Journal of Financial Economics 47 (3), 243-277.

12. Black, Fisher (1976), "Studies of stock price volatility changes", Proceedings of the 1976 meetings of the American Statistical Association, Business and Economics Statistics Section 177-181.

13. Bolton, Patrick and Ernst-Ludwig von Thadden (1998), "Blocks, Liquidity and Corporate Control", The Journal of Finance 53 (1), 1-26.

14. Boot, Arnoud, W. A., Radhakrishnan Gopalan and Anjan V. Thakor (forthcoming), "The Entrepreneur's Choice Between Private and Public Ownership", The Journal of Finance.

15. Brau, James, C. and Stanley E. Fawcett (forthcoming), "Initial Public Offerings: An Analysis of Theory and Practice", The Journal of Finance.

16. Brennan, Michael, J. and Julian Franks (1997), "Underpricing, Ownership and Control in Initial Public Offerings of Equity Securities in the UK", Journal of Financial Economics 45 (3), 391-413.

17. Burkart, Mike, Denis Gromb and Fausto Panunzi (1997), "Large Shareholders, Monitoring, and the Value of the Firm", Quarterly Journal of Economics, 112(3), 693-728.

18. Chemmanur, Thomas J. and Paolo Fulghieri (1999), "A Theory of the Going-Public Decision", Review of Financial Studies 12(2), 249-279.

19. Clarke, Ian, and William Mackaness (2001), "Management Intuition: An Interpretative Account of Structure and Content of Decision Schemas Using Cognitive Maps", Journal of Management Studies 38(2), $147-172$.

20. Coffee, John C. (1991), "Liquidity Versus Control: The Institutional Investor as Corporate Monitor", Columbia Law Review 91(6), 1277-1368.

21. Daniel, Kent, David Hirshleifer, and Avanidhar Subramaniam (1998), "Investor Psychology and Security Market under and Overreactions", The Journal of Finance 53(6), 1839-1885.

22. Detragiache, Enrica (1994), "Private versus Public Borrowing: A Theory with Implications for Bankruptcy Reform", Journal of Financial Intermediation 3, 327-354.

23. Deutsch, Claudia, "The Higher Price of Staying Public", The New York Times, January 23, 2005. 
24. Fink, Jason, Kristin Fink, Gustavo Grullon, and James P. Weston (2004), "IPO Vintage and the Rise of Idiosyncratic Risk", Working Paper, Rice University, November.

25. Galton, Francis F.R.S., and Karl Pearson (1902), "The most suitable proportion between the value of first and second prices", Biometrika 1(4), 385-399.

26. Garmaise, Mark J. (2001), "Rational Beliefs and Security Design", Review of Financial Studies 14(4), 1183-1213.

27. Gibbons, Jean Dickinson (1971), Nonparametric Statistical Inference, McGraw-Hill Series in Probability and Statistics, McGraw Hill.

28. Gomes, Armando, and Walter Nvoaes (2001), "Sharing of Control as a Corporate Governance Mechanism", Working Paper, The Wharton School.

29. Gompers, Paul A., Joy L. Ishii, and Andrew Metrick, (2003) "Corporate Governance and Equity Prices", Quarterly Journal of Economcs,118(1), 107-155.

30. Grossman, Sanford and Oliver D. Hart (1980), "Take-Over Bids, the Free Rider Problem and the Theory of the Corporation", Bell Journal of Economics and Management Science 11(1), 42-64.

31. Hart, Oliver (1995), Firms Contracts and Financial Structure, Oxford: Clarendon Press.

32. Hong, Harrison, Terence Lim and Jeremy C. Stein (2000), "Bad News Travels Slowly: Size, Analyst Coverage and the Profitability of Momentum Strategies, Journal of Finance 55, 265-296.

33. Jensen, Michael (1986), "Agency Costs of Free Cash flows, Corporate Finance and Takeovers", American Economic Review 76(2), 323-339.

34. Kaplan Steven N., and Per Stromberg (2003) "Financial Contracting Theory Meets the Real World: An Empirical Analysis of Venture Capital Contracts", The Review of Economic Studies 70 (2), 281-315.

35. Kurz, Mordecai, (1994a), "On the Structure and Diversity of Rational Beliefs", Economic Theory 4, 877-900.

36. Kurz, Mordecai, (1994b), "On Rational Belief Equilibria”, Economic Theory 4, 859-876.

37. Lerner, Josh (1995), "Venture Capitalists and the Oversight of Private Firms," The Journal of Finance 50 (1), 301-318.

38. Ljungqvist, Alexander (forthcoming), "Empirical Corporate Finance Chapter III.4: IPO Underpricing", Handbooks in Corporate Finance.

39. Maksimovic, Vojislav and Pegaret Pichler (2001), "Technological Innovation and IPOs", Review of Financial Studies 14(2), 459-494.

40. Manove, Michael and Jorge A. Padilla (1999), "Banking (Conservatively) with Optimists", RAND Journal of Economics 30(2), 324-350.

41. Maug, Ernst (1998), "Large Shareholders as Monitors: Is there a Trade-off between Liquidity and Control?", The Journal of Finance 53 (1), 65-94.

42. Morris, Stephen E.,(1995) "The Common Prior Assumption in Economic Theory", Economics and Philosophy, 11, 227-253.

43. Pagano, Marco (1993), "The Floatation of Companies on the Stock Market: A Co-ordination Failure Model", European Economic Review 37(5), 1101-1125.

44. Pagano, Marco, Fabio Panetta and Luigi Zingales (1998), "Why Do Companies Go Public ? An Empirical Analysis", Journal of Finance 53(1), 27-64.

45. Pagano, Marco and Ailsa Roell (1998), "The Choice of Stock Ownership Structure: Agency Costs, Monitoring and the Decision to go Public", Quarterly Journal of Economics 113 (1),187-225.

46. Ritter, Jay and Ivo Welch, (2002), "A review of IPO Activity, Pricing and Allocations", The Journal of Finance, 57(4), 1795-1828.

47. Rock, Kevin, (1986), "Why new issues are underpriced.", Journal of Financial Economics 15 (1-2), $187-212$

48. Ross, Stephen, A. (1977), "The Determination of Financial Structure: The Incentive-Signalling Approach", Bell Journal of Economics, 8(1), 23-40. 
49. Shah, Salman and Anjan V. Thakor (1988), "Private versus Public Ownership: Investment, Ownership Distribution, and Optimality", The Journal of Finance 43 (1), 41-59.

50. Stein, Jeremy C. (1989) "Efficient Capital Markets, Inefficient Firms: A Model of Myopic Corporate Behavior", The Quarterly Journal of Economics 104(4), 655-669.

51. Stoll, Hans R., (2000), "Friction", Journal of Finance 55, 1479-1514.

52. Thorton, Emily, "A Little Privacy Please. More Small Outfits are Deciding that Being a Public Company Isn't Worth the Hassle", Business Week May 2, 2004, 74-75.

53. Van den Steen, Eric (2004), "Rational Overoptimism (and Other Biases)", American Economic Review, 94(4), 1141-1151.

54. Von Thadden, Ernst-Ludwig (1995), "Long-Term Contracts, Short-Term Investment and Monitoring", The Review of Economic Studies, 62(4), 557-575.

55. Yerramilli, Vijay (2004), "Joint Control and Redemption Rights in Venture Capital Contracts" ECGI Finance Working Paper No. 37/2004, http://ssrn.com/abstract $=481362$.

56. Zingales, Luigi (1995), "Insider Ownership and the Decision to Go Public", The Review of Economic Studies 62(3), 425-448. 


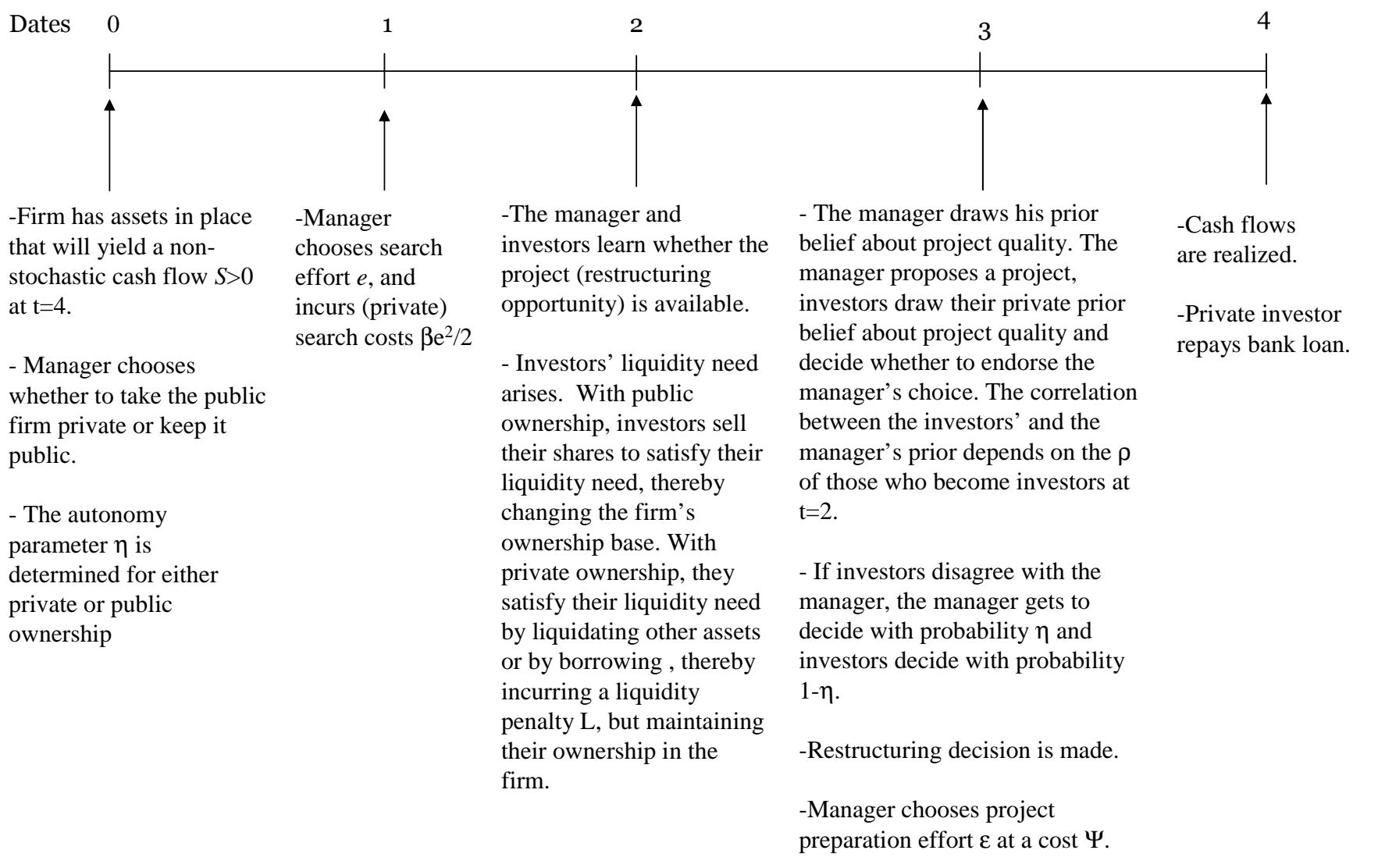

Figure 1: SEQUENCE OF EVENTS 